\title{
Genome-wide association mapping of sodium and potassium concentration in rice grains and shoots under alternate wetting and drying and continuously flooded irrigation
}

\author{
Caijin Chen ${ }^{1} \cdot$ Anthony J. Travis ${ }^{1} \cdot$ Mahmud Hossain $^{2} \cdot$ Md Rafiqul Islam $^{2} \cdot$ Adam H. Price $^{1} \cdot$ Gareth J. Norton $^{1}$ (I)
}

Received: 18 December 2020 / Accepted: 30 March 2021 / Published online: 4 May 2021

(c) The Author(s) 2021

\begin{abstract}
Key message Identification of a large number of QTL and candidate genes for sodium accumulation in a field grown population of rice derived from the aus subpopulation.

Abstract Rice (Oryza sativa L.) is a globally important cereal crop. Sodium $\left(\mathrm{Na}^{+}\right)$and potassium $\left(\mathrm{K}^{+}\right)$are the major monovalent ions which affect rice growth, and exploring their uptake mechanisms will be useful for understanding rice biology. Since the balance of $\mathrm{Na}^{+}$and $\mathrm{K}^{+}$plays a significant role in adaptation of rice to salinity, that biology might inform the search for tolerance. In this study, the $\mathrm{Na}^{+}$and $\mathrm{K}^{+}$concentration and $\mathrm{Na}^{+} / \mathrm{K}^{+}$ratio in grains and shoots were analyzed in the Bengal and Assam Aus Panel grown in field conditions under continuously flooded (CF) and alternate wetting and drying (AWD) irrigation. Overall, AWD irrigation significantly reduced the $\mathrm{Na}^{+}$concentration and increased the $\mathrm{K}^{+}$concentration in shoots and grains compared to the plants grown under CF. Genome-wide association mapping was conducted on $\mathrm{Na}^{+}$, $\mathrm{K}^{+}$concentration and $\mathrm{Na}^{+} / \mathrm{K}^{+}$ratio with 2 million SNPs using an efficient mixed model. Only QTLs which contained more than two significant SNPs $(p<0.0001)$ and where at least one of these significant SNPs passed a $10 \%$ false discovery rate were reported. A total of 106 QTLs were identified as being associated with $\mathrm{Na}^{+}$concentration and $\mathrm{Na}^{+} / \mathrm{K}^{+}$ratio across all traits and field conditions, with 48 QTLs found in multiple traits and/or water conditions. Four notable QTLs (one each on chromosomes 1 and 11, two on chromosome 2) and the haplotype variants of four candidate genes (OsHKT1;5, OsNHX2, LOC_OsO2g32490 and OsFAD2_l) are discussed. The QTLs/candidate genes identified here could be useful for breeding rice that accumulates lower concentrations of sodium.
\end{abstract}

\section{Introduction}

Rice (Oryza sativa L.) is the most important staple food crop in many countries. It is the main food source of over half of the world population, accounting for about $50-80 \%$ of daily calorie intake (Solis et al. 2020). The demand for rice is rising due to increasing populations in countries where rice is the staple food and the growing global popularity of rice cuisines (Solis et al. 2020). $\mathrm{Na}^{+}$and $\mathrm{K}^{+}$are the major monovalent ions affecting rice growth, with $\mathrm{K}^{+}$a major

Communicated by Mingliang Xu.

Gareth J. Norton

g.norton@abdn.ac.uk

1 School of Biological Sciences, University of Aberdeen, Aberdeen AB24 3UU, UK

2 Department of Soil Science, Bangladesh Agricultural University, Mymensingh, Bangladesh macronutrient for plant growth. In addition, the plant's ability to maintain $\mathrm{Na}^{+}$and $\mathrm{K}^{+}$balance is the key feature of tolerance under salt stress in rice (Negrão et al. 2011). Salt stress is a major constraint to rice acreage and production worldwide (Rohila et al. 2019). It is reported that approximately 960 million hectares of soil is salt impacted globally (Hu et al. 2012). The typical mechanisms of salinity tolerance in rice are $\mathrm{Na}^{+}$exclusion or reduced uptake, and increased absorption of $\mathrm{K}^{+}$to maintain a suitable $\mathrm{Na}^{+}-\mathrm{K}^{+}$ balance in shoots. (Negrão et al. 2011). Thus, understanding the accumulation of $\mathrm{Na}^{+}$and $\mathrm{K}^{+}$in rice is important for exploring the fundementals of rice biology and should provide useful information relevant to rice adaptation to salinity stress.

In recent decades, many quantitative trait loci (QTL) associated with $\mathrm{Na}^{+}$and $\mathrm{K}^{+}$concentration have been identified in rice using biparental mapping populations (Koyama et al. 2001; Bonilla et al. 2002; Lin et al. 2004; Ming-Zhe et al. 2005; Sabouri and Sabouri 2008; Ammar et al. 2009; 
Pandit et al. 2010; Islam et al. 2011; Ghomi et al. 2013; Hossain et al. 2015). For example, Saltol, a major QTL for $\mathrm{Na}^{+}$uptake and $\mathrm{Na}^{+} / \mathrm{K}^{+}$ratio was mapped to chromosome 1 from recombinant inbred lines derived from a cross between Pokkali (salt tolerant) and IR 29 (salt sensitive) cultivars (Bonilla et al. 2002). The OsHKT1;5 gene under the Saltol locus regulating $\mathrm{K}^{+} / \mathrm{Na}^{+}$homeostasis in the salt-tolerant indica rice cultivar Nona Bokra has been cloned using a map-based approach (Ren et al. 2005). Two major QTLs with very large effects, $q S N C-7$ for shoot $\mathrm{Na}^{+}$concentration and $q S K C-1$ for shoot $\mathrm{K}^{+}$concentration, have been identified in rice (Lin et al. 2004). There are several genome-wide association (GWA) studies in rice mapping $\mathrm{Na}^{+}, \mathrm{K}^{+}$concentration and $/$ or $\mathrm{Na}^{+} / \mathrm{K}^{+}$ratio (Kumar et al. 2015; Batayeva et al. 2018; Frouin et al. 2018; Patishtan et al. 2018; Yang et al. 2018). For instance, a total of 20 loci associated with $\mathrm{Na}^{+} / \mathrm{K}^{+}$ratio were identified, using 6000 SNPs from 220 rice accessions (Kumar et al. 2015). Eighteen QTLs were associated with $\mathrm{Na}^{+}, \mathrm{K}^{+}$concentration, and $\mathrm{Na}^{+} / \mathrm{K}^{+}$ratio, using 68,786 SNPs from 191 temperate japonica rice accessions (Batayeva et al. 2018). A significant QTL on chromosome 1-11.48 Mb (same position with Saltol) associated with $\mathrm{Na}^{+}$accumulation was identified, using 6.4 million SNPs from 529 rice cultivars in different field trials without salt stress imposed; OsHKT1; 5 was reported to be the gene responsible for this QTL (Yang et al. 2018).

Rice requires large quantities of fresh water to maintain high yields, especially in the dry season (Norton et al. 2018). It is estimated that an average of $2500 \mathrm{~L}$ of water is needed to produce $1 \mathrm{~kg}$ of rice (Bouman 2009). To reduce the volume of water needed for irrigation during the dry season, the method of alternate wetting and drying (AWD) is being promoted in some countries in Asia (Bouman and Tuong 2001; Zhang et al. 2009; Lampayan et al. 2015). AWD is a water management technique in which, during the growing season, the field is cycled between being flooded and non-flooded where the water is left to drain away naturally (Zhang et al. 2009). Once the water level has decreased to $15-20 \mathrm{~cm}$ below the soil surface, the field is re-flooded and the next AWD cycle started (Lampayan et al. 2015). It has is reported that AWD can have varying impacts on yield, ranging from no impact on yield, a decrease in yield, or am increased yield compared to permanent flooding, with an increase in yield of 35\% demonstrated in one study (Belder et al. 2004; Yang et al. 2007; Zhang et al. 2009; Carrijo et al. 2017). In addition to saving water, AWD has been reported to alter the accumulation of a range of elements in rice grains and shoots (Linquist et al. 2015; Norton et al. 2017a, b, 2019). For instance, it has been reported that AWD reduced grain $\mathrm{Na}^{+}$compared to the plants grown under continuously flooded (CF) irrigation (Norton et al. 2017a, b).

Based on genetic variation, rice can be broadly classified into five subpopulations: indica, aus, temperate japonica, tropical japonica and aromatic (Garris et al. 2005; Zhao et al. 2010; Kim et al. 2016). The aus subpopulation of rice is considered to have rich genetic diversity with wide variation in abiotic stress resistance and is grown under a range of conditions from fully irrigated to upland (Glaszmann 1987; Ali et al. 2013). Several studies have been carried out to identify $\mathrm{Na}^{+}$and $\mathrm{K}^{+}$accumulation in rice, but most used either populations of indica or japonica rice (Kumar et al. 2015; Batayeva et al. 2018; Frouin et al. 2018; An et al. 2020). Additionally, a number of the screens were done using hydroponic systems where transpiration is low and is not representative of field conditions, and the imposed stress was either not gradual enough or too severe. Little attention has been devoted to investigating $\mathrm{Na}^{+}$and $\mathrm{K}^{+}$accumulation in aus rice shoots and grains under real field conditions. This study utilizes a population of rice derived from the aus subpopulation of rice that has been genotyped and can be used for GWA mapping. This population has previously been tested for seedling-stage salt tolerance using both a hydroponic and a soil-based system (Chen et al. 2020). In the current study, the population was grown under field conditions in Bangladesh in two consecutive dry seasons under both CF and AWD conditions. The aim of this study was to understand the impact that AWD has on $\mathrm{Na}^{+}$and $\mathrm{K}^{+}$ accumulation in a wide collection of aus rice, to compare $\mathrm{Na}^{+}$and $\mathrm{K}^{+}$concentrations of field-grown plants to those screened for seedling-stage salt tolerance in hydroponic and soil systems, and to identify QTLs for $\mathrm{Na}^{+}$and $\mathrm{K}^{+}$accumulation and $\mathrm{Na}^{+} / \mathrm{K}^{+}$ratio under field conditions. The longerterm goal is to identify stable QTLs that can be utilized to reduce $\mathrm{Na}^{+}$concentration in rice, and therefore potentially breed rice that can be grown in more adverse environments.

\section{Materials and method}

\section{Materials}

The Bengal and Assam Aus Panel (BAAP) used in this study consists of 266 aus rice accessions and a small number of indica and japonica rice accessions (Table S1). The 266 aus rice accessions have been genotyped and a 2 million SNP database constructed (Norton et al. 2018).

\section{Field screening and $\mathrm{Na}$ and $\mathrm{K}$ concentration analysis}

The BAAP population was grown in the field in Mymensingh, Bangladesh, in the Boro (dry season) of 2013 and 2014 under two irrigation methods; continuously flooded irrigation $(\mathrm{CF})$ and the water saving technique alternate wetting and drying (AWD) as described in Norton et al. (2017a, 2018). Briefly, the rice seeds were initially sown in a nursery bed and then transplanted to 
the experimental field after 44 days in 2013 and 51 days in 2014. The seedlings were transplanted into eight experiment plots (four plots for AWD treatment and four plots for CF treatment); the experiment was set up as a random completed block design with four replicates. Plants were planted as two plants per hill with a distance of $20 \mathrm{~cm}$ between each hill in a row; there was a $20 \mathrm{~cm}$ gap between each row of $4 \mathrm{~m}$ length. The eight plots were flooded after transplanting. For CF treatment plots, the surface water was kept at a depth of between 2 and $5 \mathrm{~cm}$ above the soil surface during the vegetative and reproductive stage. For AWD treatment plots, plastic perforated tubes (pani pipe) were placed across the plots to monitor the water depth. This was to allow water to drain/percolate naturally from the AWD plots until the average depth of the water was $15 \mathrm{~cm}$ below the soil surface. At this point the plots were irrigated to bring the water depth to between 2 and $5 \mathrm{~cm}$ above the soil surface. AWD treatment was conducted from 14 days after transplanting until flowering. There were four AWD cycles, and once the fourth cycle had finished, the AWD and CF plots were maintained under flooded conditions during the flowering stage. The grains and shoots from every cultivar were harvested once the grains matured.

The electricity conductivity of the soil was measured using the soil water 1:5 extraction method (Visconti et al. 2010) and the exchangeable $\mathrm{Na}^{+}$and $\mathrm{K}^{+}$in the soil was measured using the ammonium acetate method (Allen et al. 1974). The particle size composition of the soil was $60.4 \%$ $( \pm 2.2(\mathrm{SD}))$ clay, $29.2 \%( \pm 2.1)$ silt, and $10.4 \%( \pm 1.5)$ sand. The $\mathrm{pH}$ of the soil was 6.6 (Norton et al. 2017a). The electrical conductivity (ECe) and $\mathrm{Na}^{+}$concentration of the soil was $0.270 \mathrm{dS} \mathrm{m}^{-1}( \pm 0.04)$ and $0.108 \mathrm{mg} \mathrm{g}^{-1}( \pm 0.029)$, respectively, which indicated the soil was not under salt stress conditions. The soil $\mathrm{K}^{+}$concentration was $0.068 \mathrm{mg} \mathrm{g}^{-1}$ $( \pm 0.008)$. The day before transplanting of seedlings into the experimental plots, the plots were fertilized with $40 \mathrm{~kg} \mathrm{ha}^{-1}$ nitrogen, $15 \mathrm{~kg} \mathrm{ha}^{-1}$ phosphorus, $50 \mathrm{~kg} \mathrm{ha}^{-1}$ potassium, $15 \mathrm{~kg} \mathrm{ha}^{-1}$ sulfur and $3 \mathrm{~kg} \mathrm{ha}^{-1}$ zinc. Further, $40 \mathrm{~kg} \mathrm{ha}^{-1}$ nitrogen was supplied during the tiller stage and another $40 \mathrm{~kg} \mathrm{ha}^{-1}$ nitrogen at the flowering stage (Norton et al. 2017a).

The $\mathrm{Na}^{+}$and $\mathrm{K}^{+}$concentrations in the shoots and grains of the rice were analyzed as described in Norton et al. (2017a). Briefly, rice grains were de-husked and oven dried $\left(80{ }^{\circ} \mathrm{C}\right)$. A total of $0.2 \mathrm{~g}$ of dehusked grains were accurately weighed out and digested with nitric acid and hydrogen peroxide (Norton et al. 2012). Shoot samples were oven dried, powdered, accurately weighed $(0.01 \mathrm{~g})$ and digested using nitric acid and hydrogen peroxide on a block digester. Analysis of $\mathrm{Na}^{+}$and $\mathrm{K}^{+}$were performed by inductively coupled plasma-mass spectroscopy (ICP-MS). Trace element grade reagents were used for all digests. For quality control, replicates of certified reference material (Oriental basma tobacco leaves [INCT- OBTL- 5] and rice flour [NIST 1568b]) were used; blanks were also included. All samples and standards contained $10 \mu \mathrm{g} \mathrm{L}^{-1}$ indium as the internal standard.

\section{Genome-wide association mapping}

GWA mapping was performed on all the aus cultivars from the BAAP using the PIQUE pipeline that first pre-processes genotype and phenotype and then conducts EMMAX analyses on each phenotype in parallel (Norton et al. 2018). SNPs with minor allele frequency (MAF) $<0.05$ were filtered out and maximum per-SNP missing percentage was set at $5 \%$ for GWA. GWA mapping was conducted with traits and 2 million SNPs using an efficient mixed model (EMMA) controlling population structure and kinship, and a significance threshold of $p<0.0001$ was used to determine significant SNPs, as described in Norton et al. (2018). The false discovery rate (FDR) of detected associations was estimated to calculate Benjamini-Hochberg adjusted probabilities (Benjamini and Hochberg 1995). A significance threshold of $10 \%$ FDR was used to identify putative SNP associations (McCouch et al. 2016) and highlighted in red in Manhattan plots. The FDR was subsequently used to identify QTLs.

\section{QTLs}

After GWA, clump analysis was conducted to identify multiple significant SNPs $(p<0.0001)$ that represent a single QTL using PLINK (Purcell et al. 2007) command "-clump- $p 1$ 0.0001 -clump- 220.0001 -clump- $r 20.3$-clump-kb 243" as described in Norton et al. (2019). Singleton significant SNPs $(p<0.0001)$ were discarded if no other SNP were within the linkage disequilibrium (LD) decay window which had a $p<0.0001$. Clump analysis was done for each trait separately. After clump analysis, the identified "clump" of all traits were put together to compare their positions; the clumps were merged into one if they were detected in different traits but in the same positions or in a $243 \mathrm{~kb}$ window. Note, $243 \mathrm{~Kb}$ is the genome-wide rate of linkage disequilibrium (LD) decay in the BAAP (Norton et al. 2018). After that, the FDR information of the significant SNPs in all QTLs was checked. Only QTLs which contained at least one significant $(p<0.0001)$ SNP that passed a $10 \%$ FDR were reported.

\section{Identification of candidate genes}

For each QTL, a genomic distance of $243 \mathrm{~kb}$ around the peak SNP of each QTL was defined and the annotation of all genes in the regions were obtained from Rice Genome Annotation Project (RGAP) (http://rice.plantbiology.msu. 
edu/), release 7. For subsequent analysis, those genes annotated as "(retro) transposon," "hypothetical," or "unknown" were excluded from the identification of candidate gene analysis. To identify which of these genes were good candidates, gene information such as gene ontology classification and gene function in RGAP were examined, and then the positions of these genes (QTLs) were compared with genes previously reported to be involved in salt stress and/ or sodium accumulation in rice from the literature.

\section{Haplotypes analysis}

Four notable QTLs which were associated with multiple traits were further investigated. LD heatmaps surrounding the peaks of these QTLs were constructed using the R package "LDheatmap" using squared Pearson's correlation coefficient $\left(r^{2}\right)$. The gene expression profiles of all genes within the Local LD region were obtained from different studies (Walia et al. 2007; Shankar et al. 2016; Buti et al. 2019; Campbell et al. 2020) to confirm the validity of candidate genes. The SNPs which were significantly $(p<0.01)$ associated with the $\mathrm{Na}^{+}$concentration and/or $\mathrm{Na}^{+} / \mathrm{K}^{+}$ratio were extracted using PLINK. Non-synonymous and synonymous SNPs within the genes were identified based on the gene models of the annotated Nipponbare reference genome from RGAP using ANNOVAR software (Wang et al. 2010). The haplotypes based on visualization of the SNPs in the exon of the candidate genes in these four QTLs were determined and phenotypic response for the cultivars with each haplotype were observed.

\section{Statistical analysis}

The cultivars which had phenotypic data in both AWD and CF conditions were used to do the two-way ANOVA using the software Minitab v.19 (State College, PA, United States). The boxplot, interplot, and Pearson correlation analysis were performed using the package "ggplot2" in R version 4.0. Principal component analysis for traits was performed using the package "factoextra" in $\mathrm{R}$ version 4.0. The plot of QTLs and candidate genes in different chromosomes were performed using the packages "plotrix" and "shape" in R version 4.0.

\section{Results}

\section{$\mathrm{Na}^{+}, \mathrm{K}^{+}$concentration and $\mathrm{Na}^{+} / \mathrm{K}^{+}$ratio under AWD and $\mathrm{CF}$}

There were significant differences between all measured traits, except grain $\mathrm{K}^{+}$concentration in year 2 , between the plants grown in AWD and CF. In both years grain and shoot
$\mathrm{Na}^{+}$concentration was lower in the plants grown under AWD (Fig. 1). In year 1 , the average $\mathrm{Na}^{+}$concentration of grains and shoots across the population in AWD treatment ( $8.6 \mathrm{mg} \mathrm{kg}^{-1}$ and $2556 \mathrm{mg} \mathrm{kg}^{-1}$, respectively) were significantly lower than that in CF treatment $\left(10.9 \mathrm{mg} \mathrm{kg}^{-1}\right.$ and $3120 \mathrm{mg} \mathrm{kg}^{-1}$, respectively). The average $\mathrm{Na}^{+} / \mathrm{K}^{+}$ratio of grains and shoots in plants grown under AWD were $0.28 \%$ and $14.9 \%$, respectively, which were significantly lower than plants grown under CF conditions $(0.37 \%$ and $21.8 \%$, respectively). In year 2 , the average $\mathrm{Na}^{+}$concentration and $\mathrm{Na}^{+} / \mathrm{K}^{+}$ratio in the grains of plants grown under AWD $\left(7.7 \mathrm{mg} \mathrm{kg}^{-1}\right.$ and $0.24 \%$, respectively) were significantly lower than the plants grown under CF conditions (9.5 $\mathrm{mg} \mathrm{kg}^{-1}$ and $0.31 \%$ ) (Table S2). There were significant genotype and treatment effects in all measured traits in both years while only the $\mathrm{Na}^{+}$concentration and $\mathrm{Na}^{+} / \mathrm{K}^{+}$ratio in grains in year 2 showed significant genotype $\times$ treatment interactions (Table 1). There were large variations between cultivars for $\mathrm{Na}^{+}$concentration, $\mathrm{K}^{+}$concentration and $\mathrm{Na}^{+}$/ $\mathrm{K}^{+}$ratio with the proportion of variation explained by genotype being between 27.8 and $41.7 \%$ (Table 1 ).

Correlations between the corresponding traits under AWD and CF conditions were significant $\left(p<1 \times 10^{-8}\right)$ (Fig. $\mathrm{S} 1$ ), with the correlation coefficient $(r)$ of 0.46 and 0.65 for $\mathrm{Na}^{+}$concentration in shoots and grains, respectively, 0.48 and 0.44 for $\mathrm{K}^{+}$concentration in shoots and grains, respectively, 0.63 and 0.65 for $\mathrm{Na}^{+} / \mathrm{K}^{+}$ratio in shoots and grains, respectively, in year 1 , and 0.68 for grain $\mathrm{Na}^{+}, 0.4$ for grain $\mathrm{K}^{+}$and 0.7 for grain $\mathrm{Na}^{+} / \mathrm{K}^{+}$ratio in year 2 .

\section{PCA analysis}

To investigate the relationship among trait variables and the factors underlying trait variation, principal component analysis (PCA) was performed for all 18 traits (Fig. 2; Fig. S2 and Table S3). PC1, PC2 and PC3 explained 40.2\%, 12.9\% and $10.3 \%$ of trait variance, respectively. Traits clearly occupied different spaces in the biplot with shoot $\mathrm{K}^{+}$having negative values for both $\mathrm{PC}$ axis, grain $\mathrm{K}^{+}$traits being slightly positive for PC1 and highly negative for PC2, while all $\mathrm{Na}^{+}$traits including $\mathrm{Na}^{+} / \mathrm{K}^{+}$ratio had very large positive values for PC1 and near zero for PC2. Among the $\mathrm{Na}^{+}$ traits, shoot traits (including $\mathrm{Na}^{+} / \mathrm{K}^{+}$ratio) were the most positive for PC2.

\section{Aus subpopulation analysis}

The BAAP population can be divided into five distinct groups by analysis of the population structure (Norton et al. 2018) (Table S1). One-way ANOVA showed that there were significant $(p<0.01)$ variations among these five groups in $\mathrm{Na}^{+}, \mathrm{K}^{+}$concentration and $\mathrm{Na}^{+} / \mathrm{K}^{+}$ratio (Fig. 3; Table S4). The proportion of variation explained by structure groups 
Fig. $1 \mathrm{Na}^{+}, \mathrm{K}^{+}$concentration and $\mathrm{Na}^{+} / \mathrm{K}^{+}$ratio in grains and shoots under AWD and $\mathrm{CF},{ }^{*} p<0.05, * * p<0.01$, $* * * p<0.001$. Year 1 is year 2013, while year 2 is year 2014
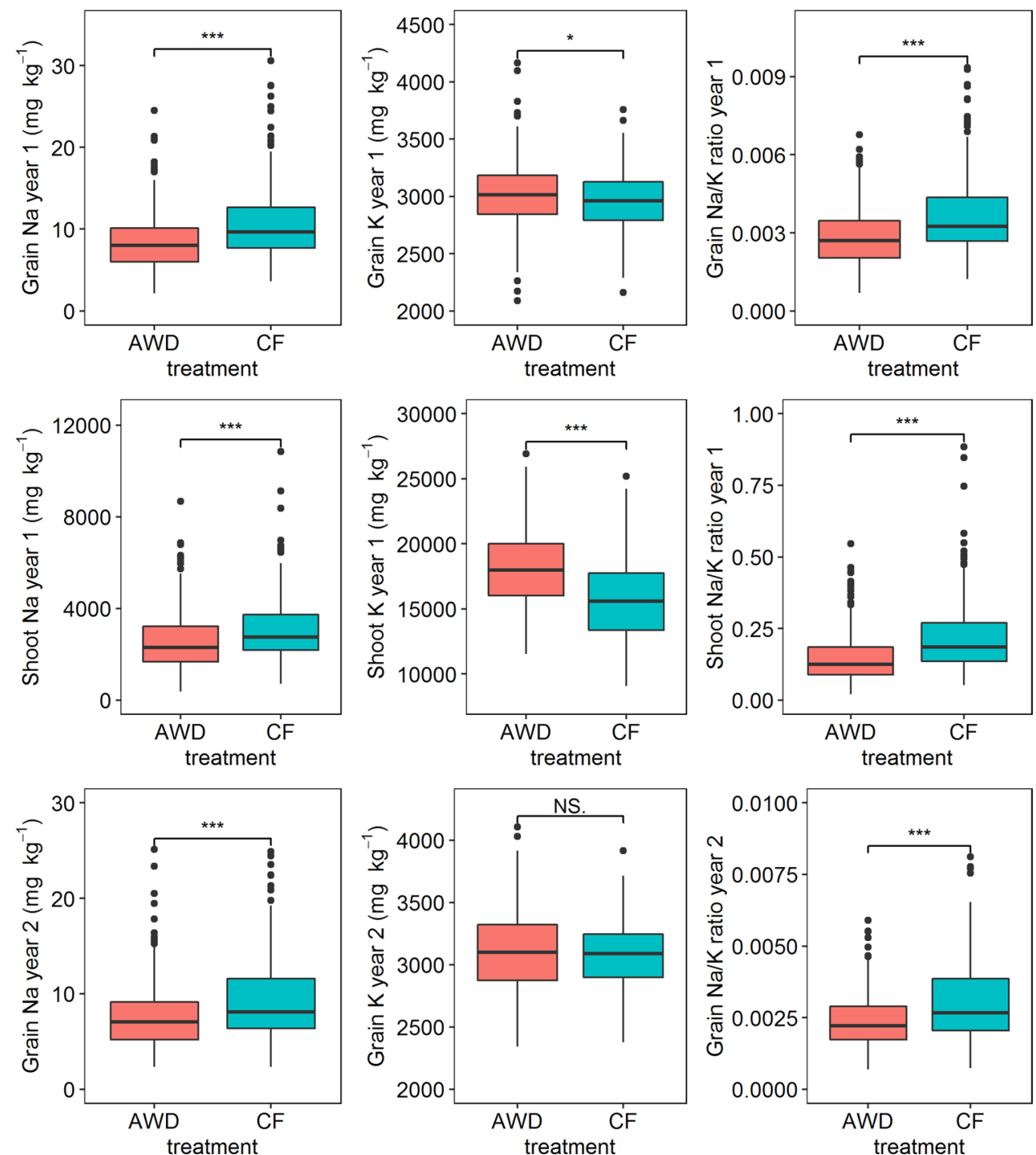

were between 6.9 and $47.3 \%$, with the $\mathrm{Na}^{+} / \mathrm{K}^{+}$ratio in shoots in year 1 having the largest values (AWD: $47.0 \%$; $\mathrm{CF}$ : $47.3 \%$ ), and the $\mathrm{K}^{+}$concentration in grains in year 2 having the smallest values (AWD: 6.9\%; CF: 7.3\%) (Table S4). Comparison of the $\mathrm{Na}^{+}, \mathrm{K}^{+}$concentration and $\mathrm{Na}^{+} / \mathrm{K}^{+}$ratio in different structure groups showed that the cultivars in groups 2 and 3 were high for grain $\mathrm{Na}^{+}$concentration and grain $\mathrm{Na}^{+} / \mathrm{K}^{+}$ratio while groups 1,4 and 5 were low. The cultivars in group 2 had high value for grain $\mathrm{K}^{+}$concentration and group 5 had the lowest grain $\mathrm{K}^{+}$concentration. For shoots, the cultivars in group 3 had the highest values in $\mathrm{Na}^{+}$ concentration and $\mathrm{Na}^{+} / \mathrm{K}^{+}$ratio and the lowest values in $\mathrm{K}^{+}$ concentration, while group 5 had the lowest values in $\mathrm{Na}^{+}$ concentration and $\mathrm{Na}^{+} / \mathrm{K}^{+}$ratio but the highest values in $\mathrm{K}^{+}$ concentration (Fig. 3). 
Fig. 2 PCA for $\mathrm{Na}^{+}, \mathrm{K}^{+}$ concentration and $\mathrm{Na}^{+} / \mathrm{K}^{+}$ratio under AWD and $\mathrm{CF}$ conditions. Y1: year 2013; Y2: year 2014. Contri means the contribution to the PCs

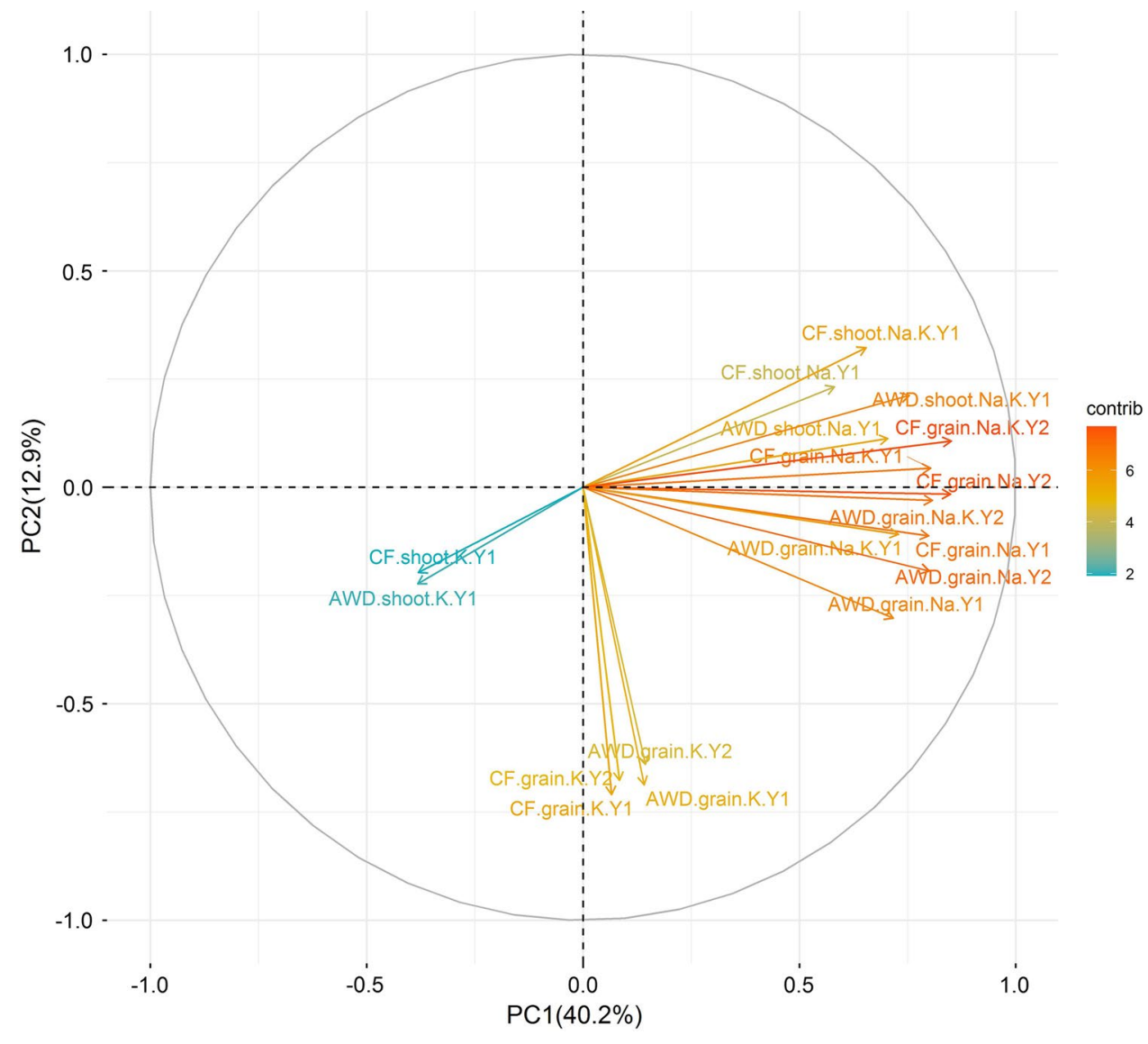

\section{Comparison of $\mathrm{Na}^{+}$and $\mathrm{K}^{+}$concentration in the BAAP under different screening conditions}

The BAAP has been screened for salt tolerance at the seedling stage under both a hydroponic (EC: $7 \mathrm{dS} \mathrm{m}^{-1}$ ) and a soil (EC: gradually increased from 2 to $9 \mathrm{dS} \mathrm{m}^{-1}$ ) system, and $\mathrm{Na}^{+}$and $\mathrm{K}^{+}$concentrations in shoots were measured (Chen et al. 2020). In this study, the $\mathrm{Na}^{+}$and $\mathrm{K}^{+}$concentrations in shoots and grains were measured in field conditions. Correlations between the $\mathrm{Na}^{+}$and $\mathrm{K}^{+}$concentration in different experiments (field, soil and hydroponic) were conducted (Table S5). The $\mathrm{Na}^{+}$concentration in shoots and grains under AWD and CF conditions in field in both years positively correlated $(p<0.05)$ with $\mathrm{Na}^{+}$concentration in shoots in hydroponics ( $r$ ranged from 0.18 to 0.32 ) and $\mathrm{Na}^{+}$concentration in shoots in soil controlled environment experiment ( $r$ ranged from 0.18 to 0.32 ). There were no significant correlations for $\mathrm{K}^{+}$concentration in plants grown in the field and in hydroponic environments, while the $\mathrm{K}^{+}$ concentration in shoots of plants grown in field under both AWD and CF conditions were significantly $(p<0.05)$ positively correlated with $\mathrm{K}^{+}$concentration in shoots of plants grown in soil environment, with the correlation coefficient 0.20 and 0.18 , respectively. For $\mathrm{Na}^{+} / \mathrm{K}^{+}$ratio, except for the
CF shoot $\mathrm{Na}^{+} / \mathrm{K}^{+}$ratio in year 1 , the $\mathrm{Na}^{+} / \mathrm{K}^{+}$ratio in shoots and roots in field conditions positively correlated $(p<0.05)$ with $\mathrm{Na}^{+} / \mathrm{K}^{+}$in shoots in hydroponics ( $\mathrm{r}$ ranged from 0.15 to 0.31 ). The $\mathrm{Na}^{+} / \mathrm{K}^{+}$ratio in shoots of plants grown under both $\mathrm{CF}$ and AWD in field were positively significantly $(p<0.01)$ correlated with shoots $\mathrm{Na}^{+} / \mathrm{K}^{+}$ratio in plants grown in the soil-controlled environment experiment $(r$ ranged from 0.27 to 0.30 ).

\section{GWA mapping for $\mathrm{Na}^{+}$concentration and $\mathrm{Na}^{+}$ratio}

GWA mapping was conducted on the BAAP to identify genomic loci controlling $\mathrm{Na}^{+}$and $\mathrm{K}^{+}$concentration and $\mathrm{Na}^{+}$/ $\mathrm{K}^{+}$ratio in grains and shoots in rice plants (Fig. 4, Fig. S3 and Fig. S4).

In total, 106 QTLs were associated with at least one of the 12 investigated traits (Table S6); 48 of the QTLs were associated with $\mathrm{Na}^{+}$and/or $\mathrm{Na}^{+} / \mathrm{K}^{+}$ratio in multiple years and/or multiple conditions (Table 2). Several QTLs were notable in terms of containing a large number of significant SNPs and with multiple traits associated with the QTL. The notable QTLs were on chromosome 1 around $11.45 \mathrm{Mb}$, which was detected in ten traits; on chromosome 11 between 25.63 and $26.06 \mathrm{Mb}$, which was detected in seven traits; 

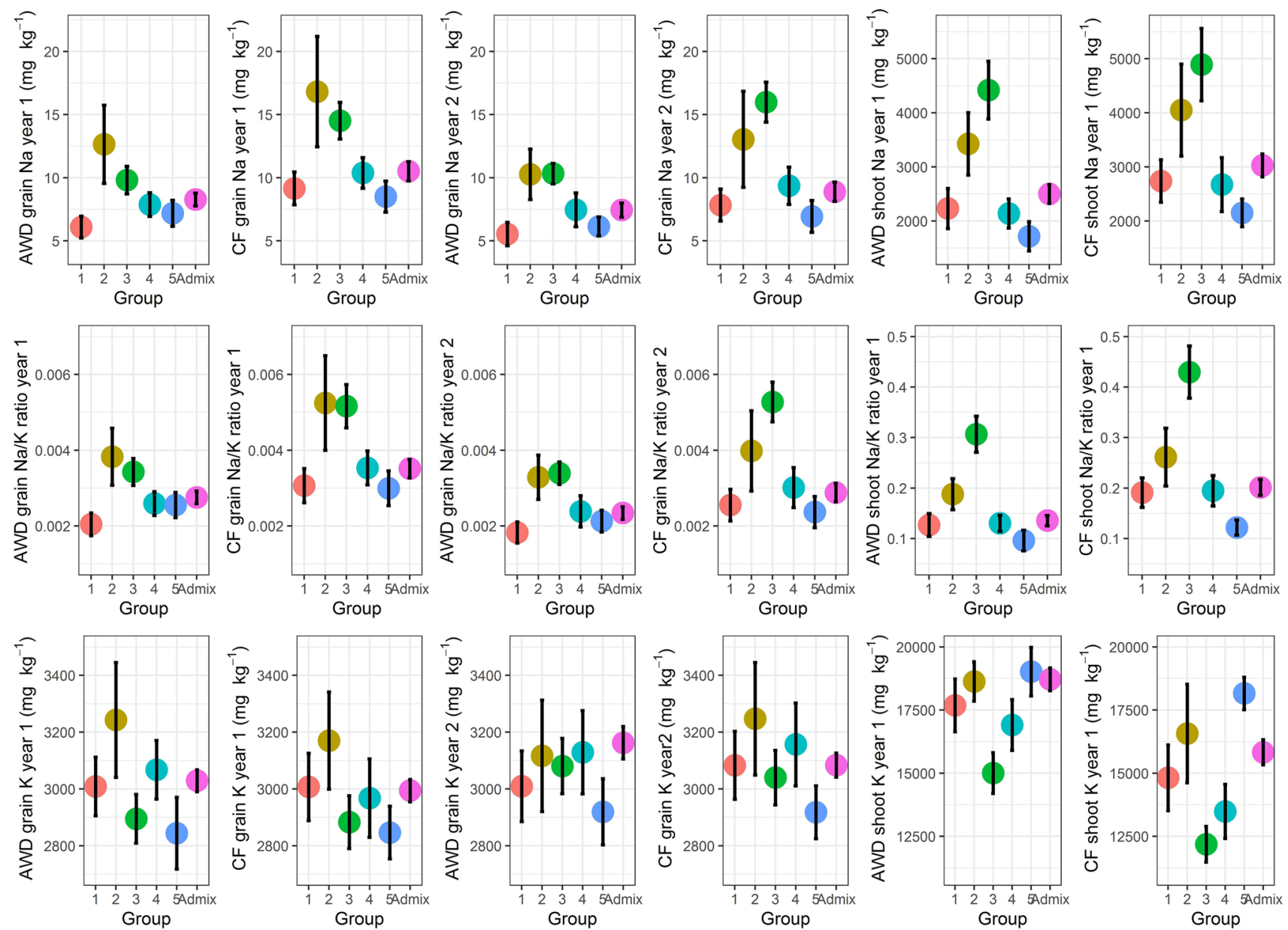

Fig. 3 Range of $\mathrm{Na}^{+}, \mathrm{K}^{+}$concentration and $\mathrm{Na}^{+} / \mathrm{K}^{+}$ratio in grains and shoots variations under different BAAP groups. Bar is $95 \%$ confidence interval. BAAP groups as identified by Norton et al. (2018)

on chromosome 2 between 19.20 and $19.25 \mathrm{Mb}$, which was detected in four traits; and on chromosome 2 between 29.66 and $30.14 \mathrm{Mb}$, which was detected in three traits. In addition, the QTLs on chromosome $5(\sim 3.34 \mathrm{Mb})$, chromosome $6(\sim 25.10 \mathrm{Mb})$ and the QTL on chromosome 11 $(\sim 20.75 \mathrm{Mb})$ were all associated with two traits.

\section{Haplotypes analysis}

The notable QTL on chromosome 1-11.45 Mb was associated with $\mathrm{Na}^{+}$concentration and $\mathrm{Na}^{+} / \mathrm{K}^{+}$ratio in shoot and grains in both years and both water treatments (Fig. 4 and Fig. S4). The QTL region was estimated to be from 11.24 to $11.52 \mathrm{Mb}$ by pairwise LD correlations (Fig. 5a). There are 25 genes in this QTL region based on RGAP (Table S7). Among them, 15 genes have previously been shown to be either significantly differentially expressed due to salt treatment or to have different expression between cultivars (Walia et al. 2007; Shankar et al. 2016; Buti et al. 2019; Campbell et al. 2020) (Table S7). LOC_Os01g20160
(OsHKT1; 5) was selected as the candidate gene as the transcript levels of this gene in 91 rice accessions are highly divergent, and RNA expression of M103 (salt sensitive cultivar) and Agami (salt tolerance cultivar) were significantly $(p<0.001)$ different under both control and salt stress conditions during the panicle initiation stage (Table S7). A total of 34 SNPs in this candidate gene are listed in the BAAP 2 million SNP database, and five of them are in the exons of this gene, four of which were nonsynonymous SNPs. The physical positions (based from the start of the chromosome) of these four nonsynonymous SNPs were at 11,460,344 bp (C/A polymorphism), 11,462,725 bp (G/A polymorphism), $11,462,858 \mathrm{bp}$ (G/C polymorphism) and 11,463,271 bp (G/A polymorphism), which resulted in the amino acid substitutions from $\mathrm{Gln}(\mathrm{Q})$ to Lys $(\mathrm{K}), \operatorname{Arg}(\mathrm{R})$ to His $(\mathrm{H})$, Ala (A) to Pro $(\mathrm{P})$ and Ser $(\mathrm{S})$ to Asn $(\mathrm{N})$, respectively. In addition, a synonymous polymorphism was at $11,462,124 \mathrm{bp}(\mathrm{G} / \mathrm{A})$ (Fig. 5b). The cultivars in this study carried three haplotypes for these five SNPs, A $(n=10), \mathrm{B}(n=158)$ and C $(n=66)$ (Fig. 5b). The cultivars carrying A and B haplotypes showed 


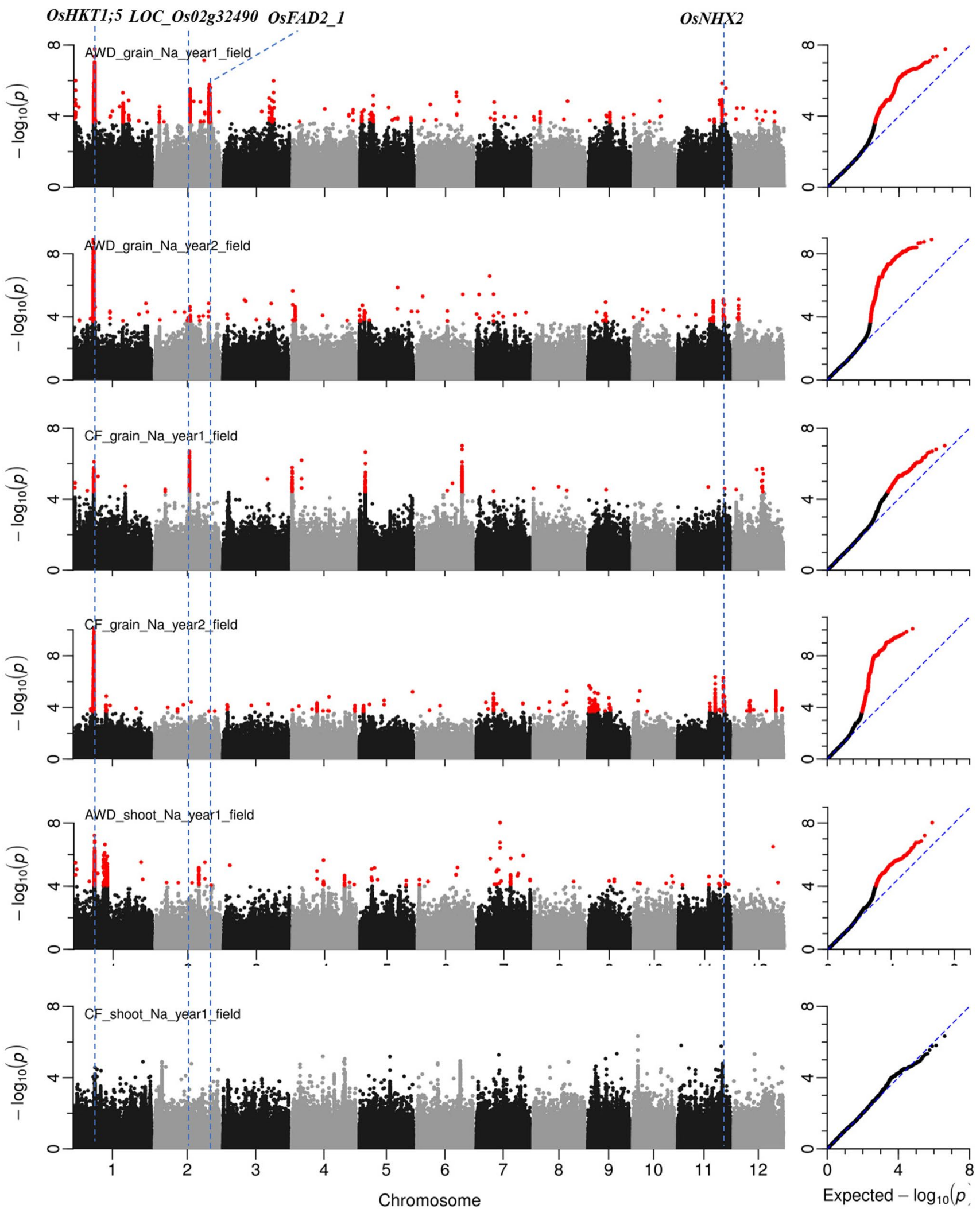

Fig. 4 Manhattan plots from GWA mapping of $\mathrm{Na}^{+}$concentration in grains and shoots under CF and AWD. Benjamini-Hochberg adjusted probabilities $>0.1$ are highlighted in red dot. The diagonal blue line shown on QQ Plots represents 1:1 agreement between expected probability. Candidate genes for four notable QTLs are shown along on the top 


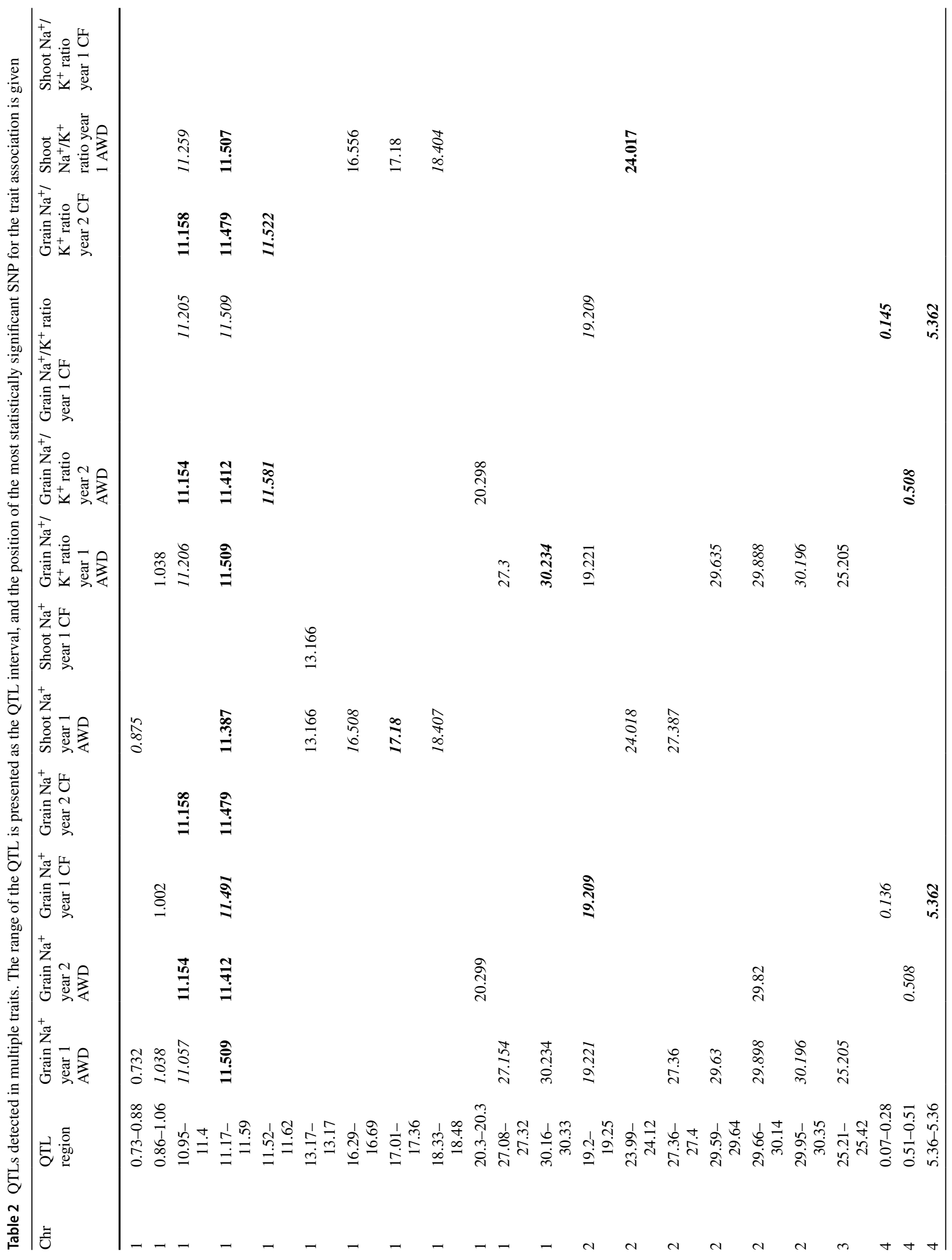




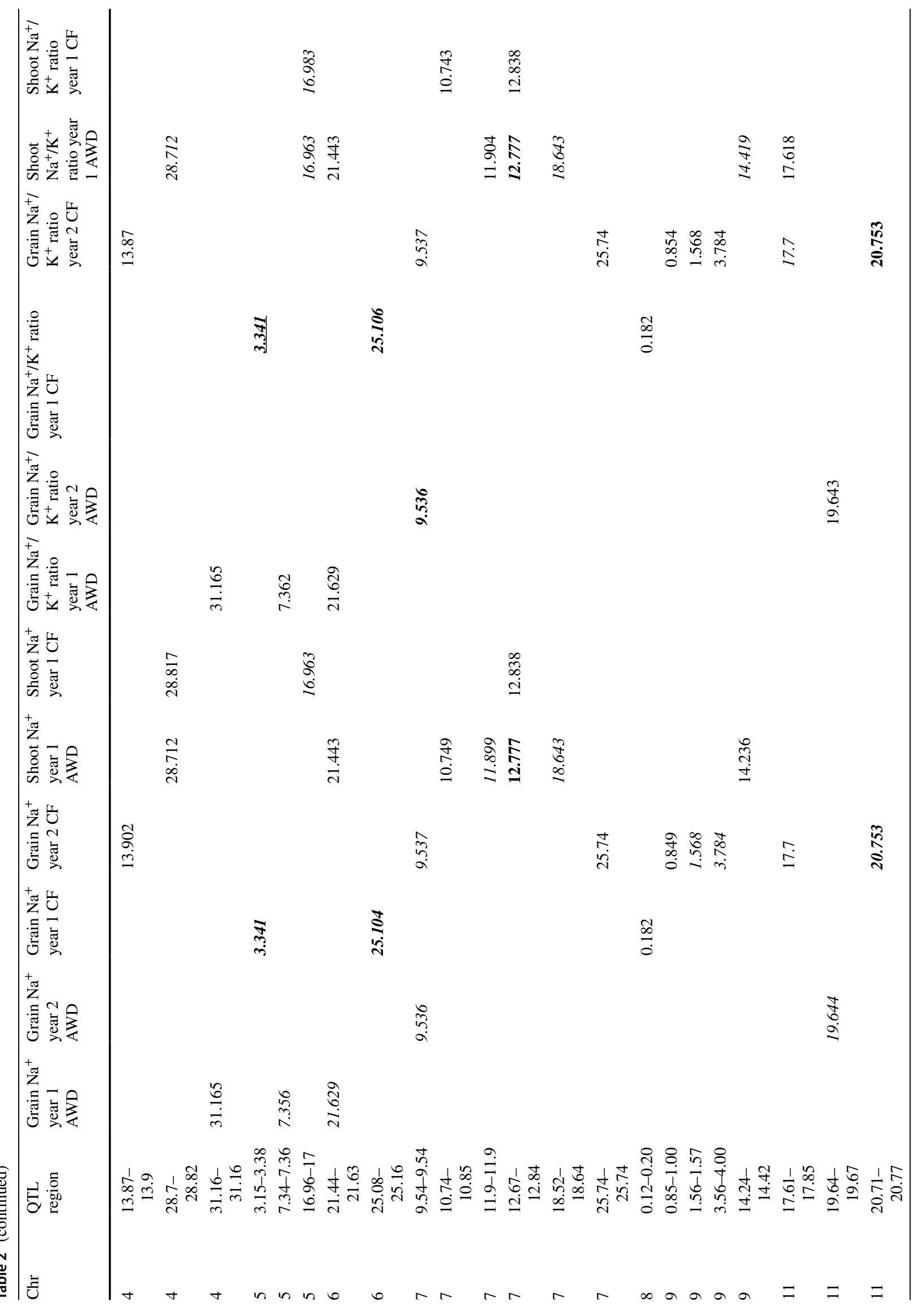




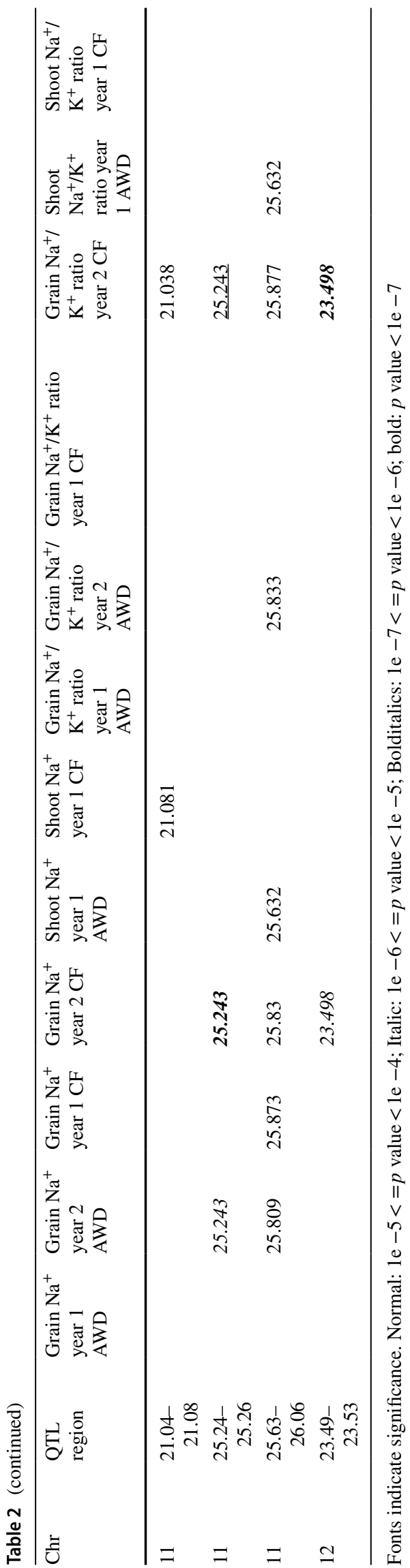

significantly lower grain and shoot $\mathrm{Na}^{+}$concentration and $\mathrm{Na}^{+} / \mathrm{K}^{+}$ratio (Fig. $5 \mathrm{c}$ and Fig. S5) while $\mathrm{K}^{+}$concentrations were not significantly different (data not presented).

A strong QTL on chromosome $11-25.80 \mathrm{Mb}$ was associated with $\mathrm{Na}^{+}$concentration and $\mathrm{Na}^{+} / \mathrm{K}^{+}$ratio in grains and shoots (Fig. 4 and Fig. S4). The QTL region was estimated to be from 25.76 to $25.98 \mathrm{Mb}$ (Fig. 6). There were 21 genes in this QTL region. Among them, 12 genes have previously been shown to be either significantly differentially expressed due to salt treatment or to have different expression between cultivars (Walia et al. 2007; Shankar et al. 2016; Buti et al. 2019; Campbell et al. 2020) (Table S8). LOC_Os11g42790 (OsNHX2) which is annotated as a monovalent cation: proton antiporter was selected as the candidate gene in this region (Fig. 6a). The expression of this gene in cultivars N22 and Vialone Nano in salt stress was significantly $(p<0.001)$ upregulated, and the RNA expression was significantly $(p<0.001)$ different between M103 and Agami under control condition during the panicle initiation stage (Walia et al. 2007; Shankar et al. 2016; Buti et al. 2019) (Table S8). Seven SNPs in the exons of the gene were significantly associated with traits, three of which were nonsynonymous SNPs. These three nonsynonymous SNPs were at the positions $25,768,996 \mathrm{bp}$ (T/C polymorphism), $25,770,750 \mathrm{bp}$ (A/G polymorphism), and 25,772,135 bp (A/G polymorphism), which resulted in a change at amino acid from Ile (I) to Thr (T), Ser (S) to Gly (G) and Met (M) to Val (V), respectively. Four synonymous polymorphisms were at 25,770,039 bp (C/A), 25,770,589 bp (C/T), $25,770,793 \mathrm{bp}$ (T/A) and 25,770,843 bp (T/C) (Fig. 6b). The cultivars carried two haplotypes for these seven SNPs, the common $(n=191)$ A haplotype and rarer $(n=29)$ B haplotype (Fig. 6b, c). The $\mathrm{Na}^{+}$concentration in grains in these two haplotypes were significantly different. The cultivars carrying the A haplotypes had lower grain $\mathrm{Na}^{+}$content than cultivars carrying the B haplotype (Fig. 6c and Fig. S6).

Another notable QTL is on chromosome $2-19.20 \mathrm{Mb}$ which was associated with $\mathrm{Na}^{+}$concentration and $\mathrm{Na}^{+} / \mathrm{K}^{+}$ ratio in grains in both AWD and CF conditions (Fig. 4 and Fig. S4). The QTL region was estimated to be from 19.20 to 19.24 Mb by using pairwise LD correlations (Fig. 7a). There are five genes in this local LD region. Among them, four genes have previously been shown to be either significantly differentially expressed due to salt treatment or to have different expression between cultivars (Walia et al. 2007; Shankar et al. 2016; Buti et al. 2019; Campbell et al. 2020) (Table S9). The gene LOC_OsO2g32490 which is annotated as AMP-binding enzyme was proposed as the candidate gene based on the RNA expression. The RNA levels in a salt sensitive cultivar (Vialone Nano) were significantly $(p<0.001)$ upregulated under salt stress. Additionally the transcript levels of LOC_OsO2g32490 in 91 rice accessions was highly divergent under control conditions, and the RNA expression 


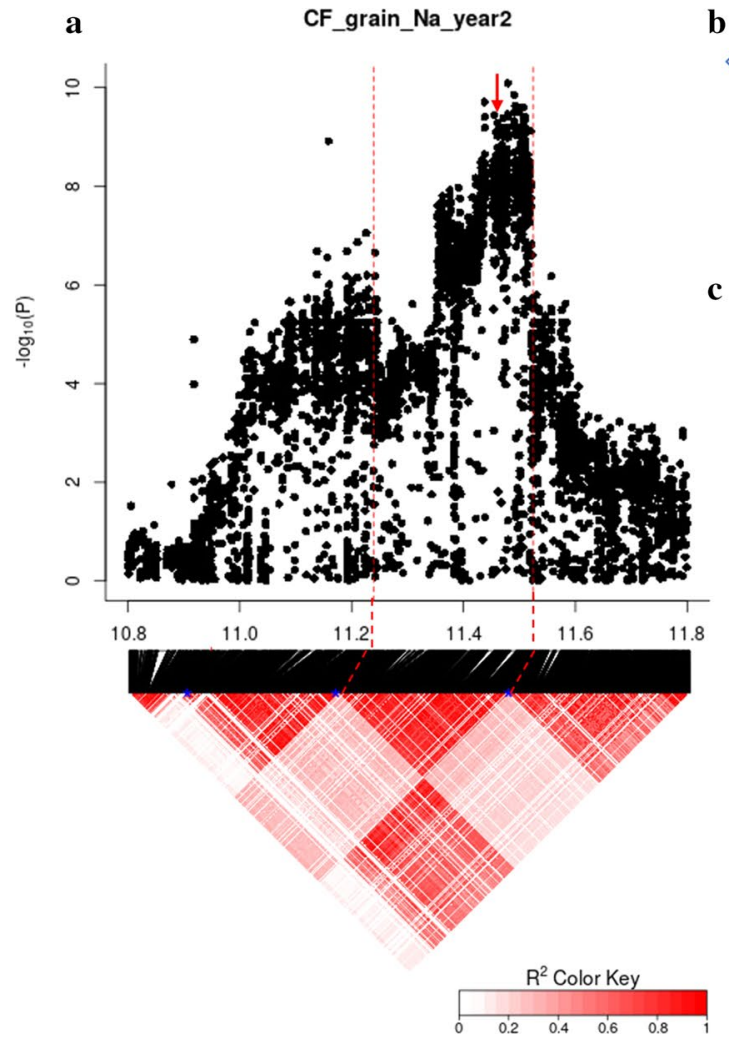

Fig. 5 Significant association for $\mathrm{Na}^{+}$concentration and $\mathrm{Na}^{+} / \mathrm{K}^{+}$ ratio in the grains and shoots on chromosome $1-11.45 \mathrm{Mb}$. a Local Manhattan plot (top) and LD heat map (bottom) of QTL on Chromosome 1, dash line represents the candidate regions between 11.25 and $11.52 \mathrm{Mb}$. Arrow indicates the position of candidate gene $\mathrm{LOC}_{-}$ b LOC_Os01g20160(OsHKT1:5)
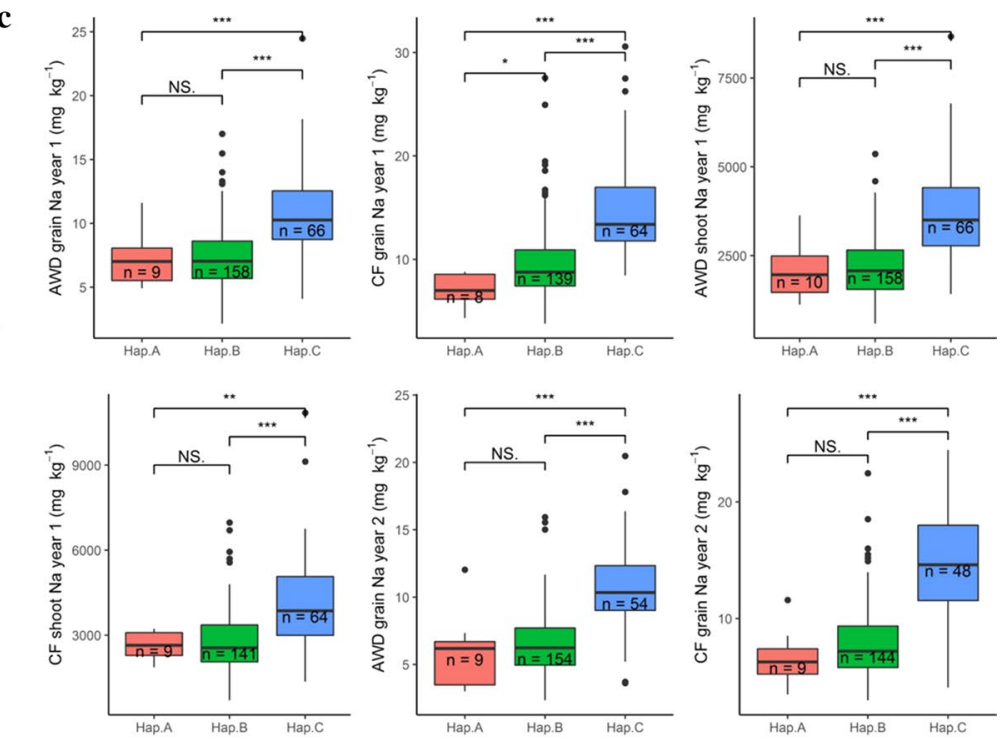

of M103 and Agami were significantly $(p<0.001)$ different under control conditions during the panicle initiation stage (Walia et al. 2007; Buti et al. 2019; Campbell et al. 2020) (Table S9). There were 22 SNPs in LOC_OsO2g32490 in the BAAP; five of them were SNPs in the exons which are significantly associated with $\mathrm{Na}^{+}$, while three of them were nonsynonymous SNPs. These three nonsynonymous SNPs were at the positions 19,220,252 bp (A /G polymorphism), $19,220,304 \mathrm{bp}$ (C/T polymorphism), and 19,220,335 bp ( $\mathrm{T} / \mathrm{G}$ polymorphism) which resulted in a change at amino acid from Ile (I) to Val (V), Pro (P) to Leu (L), and Asp (D) to Glu (E). Two synonymous polymorphisms were 19,223,158 bp (T/C) and 19,224,156 bp (G/A) (Fig. 7b). The cultivars carried two haplotypes for these five SNPs, a rare $(n=22)$ A haplotype and a common $(n=197)$ B haplotype (Fig. $7 b, c)$. The $\mathrm{Na}^{+}$concentration in grains in these two haplotypes were significantly different. The cultivars carrying the A haplotype had higher $\mathrm{Na}^{+}$concentration and $\mathrm{Na}^{+} /$ $\mathrm{K}^{+}$ratio in grains than cultivars carrying the $\mathrm{B}$ haplotype in both years and under both water treatments (Fig. 7c).

Another notable QTL on Chromosome 2-29.9 Mb was significantly associated with grain $\mathrm{Na}^{+}$concentration and $\mathrm{Na}^{+} / \mathrm{K}^{+}$
Os01g20160 (OsHKT1;5); b the synonymous and nonsynonymous SNPs in the candidate gene $O s H K T 1 ; 5$ significantly associated with $\mathrm{Na}^{+}$, and amino acid variations; $\mathbf{c} \mathrm{Na}^{+}$concentration in grains and shoots for indicated haplotypes of OsHKT1;5

ratio in plants grown under AWD irrigation (Fig. 4; Fig. S4). The QTL region was estimated to be from 29.59 to $30.30 \mathrm{Mb}$ by using pairwise LD correlations (Fig. 8a); this region contains 100 annotated genes. Among them, 85 genes have previously been shown to be either significantly differentially expressed due to salt treatment or to have different expression between cultivars (Walia et al. 2007; Shankar et al. 2016; Buti et al. 2019; Campbell et al. 2020) (Table S10). Based on genes' function and their RNA expression (Table S8), gene LOC_OsO2g48560 (OsFAD2_l) annotated as fatty acid desaturase was proposed as the candidate gene in this locus. The RNA level in LOC_OSO2g48560 was significantly $(p<0.05)$ downregulated under salt stress in both sensitive and tolerant cultivars (Buti et al. 2019), and the RNA expression of this gene in M103 and Agami were significantly $(p<0.001)$ different under control conditions during the panicle initiation stage (Walia et al. 2007) (Table S10). There were 20 SNPs in the LOC_OsO2g48560 (OsFAD2_l) and no nonsynonymous SNPs were found. The cultivars in the BAAP carried three haplotypes among these 20 SNPs, I $(n=205)$, II $(n=10)$ and III $(n=10)$. The $\mathrm{Na}^{+}$concentration and $\mathrm{Na}^{+} / \mathrm{K}^{+}$ratio in grains in I haplotype were significantly lower than that in III haplotype (Fig. 8b). 


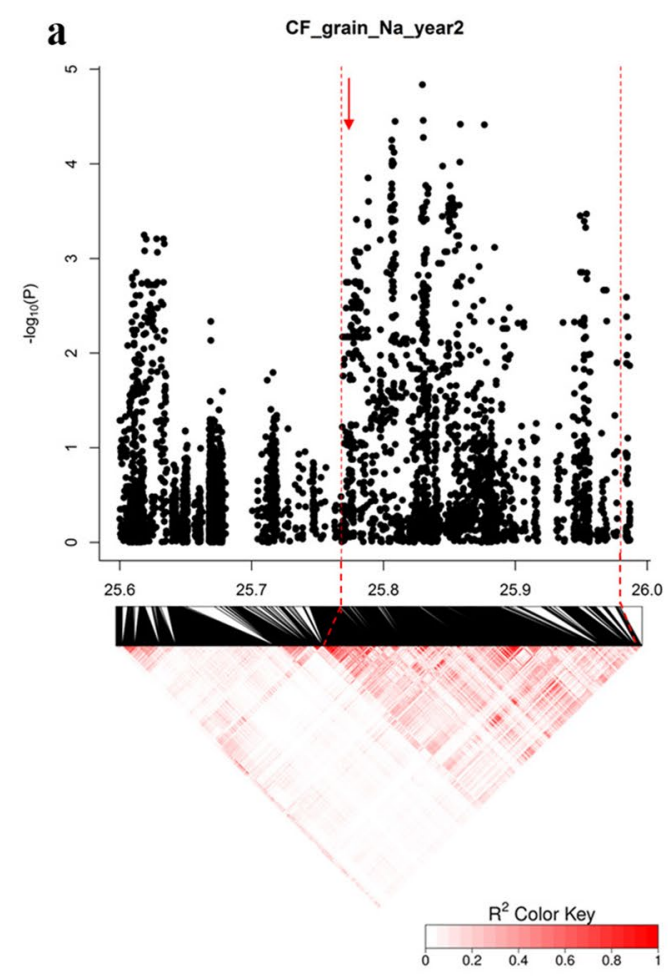

b

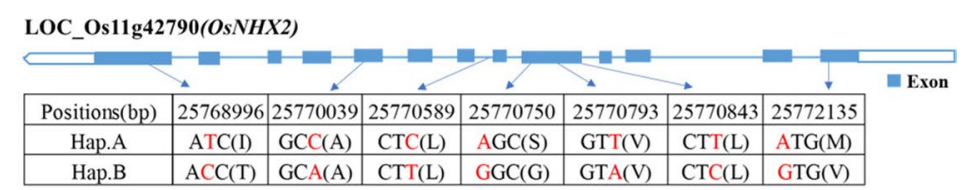

c
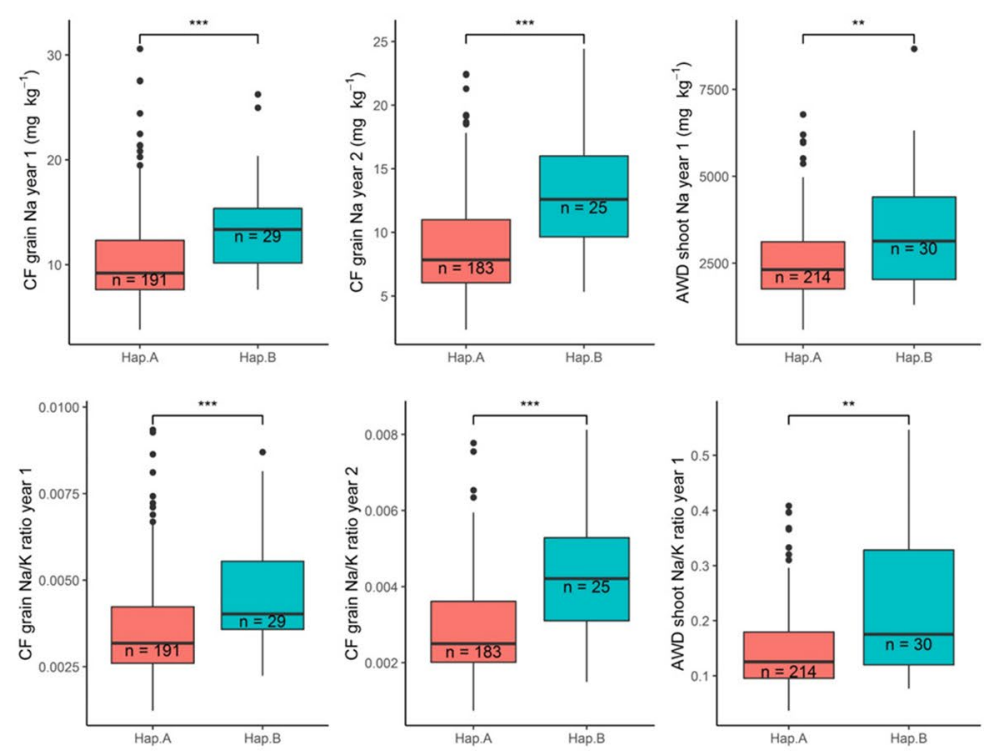

Fig. 6 Significant association for $\mathrm{Na}^{+}$concentration and $\mathrm{Na}^{+} / \mathrm{K}^{+}$ ratio in the grains and shoots on chromosome 11-25.80 Mb. a Local Manhattan plot (top) and LD heat map (bottom) of QTL on Chromosome 11, dash line represents the candidate regions between 25.75 and $25.98 \mathrm{Mb}$. Arrow indicates the position of candidate gene $L O C_{-}$

\section{Discussion}

\section{Comparison of $\mathrm{Na}^{+}$and $\mathrm{K}^{+}$concentration and $\mathrm{Na}^{+} / \mathrm{K}^{+}$ ratio in plants grown under AWD and CF conditions}

Several studies have reported that the accumulation of a range of elements were different under AWD irrigation compared to CF (Chou et al. 2016; Norton et al. 2017b, 2019). Grain $\mathrm{Na}^{+}$and $\mathrm{K}^{+}$concentration both decreased under AWD irrigation in a panel of 22 cultivars, of which 19 are in the BAAP (Norton et al. 2017b). In this study, more BAAP cultivars $(n=284)$ were used to test the impact of AWD irrigation on $\mathrm{Na}^{+}$and $\mathrm{K}^{+}$concentration. The results also showed that the grain $\mathrm{Na}^{+}$and shoot $\mathrm{Na}^{+}$concentration across the population decreased in AWD, while the grain $\mathrm{K}^{+}$and shoot $\mathrm{K}^{+}$concentration across the population increased under AWD irrigation (except for the grain $\mathrm{K}^{+}$in year 2) (Fig. 1). Under CF conditions there is more leaching of applied fertilizer (such as N, P, K), compared to AWD (Islam et al. 2016). This phenomenon of leaching in CF could be the reason why the plants uptake less $\mathrm{K}^{+}$when grown under $\mathrm{CF}$
Os11g42790 (OsNHX2) (Positioned at $25.77 \mathrm{Mb}$ ); b the synonymous and nonsynonymous SNPs in the candidate gene OsNHX2 significantly associated with the $\mathrm{Na}^{+}$, and amino acid variations; $\mathbf{c} \mathrm{Na}^{+}$ concentration and $\mathrm{Na}^{+} / \mathrm{K}^{+}$ratio in grains for indicated haplotypes of OsNHX2

compared to AWD. The results of $\mathrm{Na}^{+}$and $\mathrm{K}^{+}$concentration in plants grown under AWD and CF may suggest that AWD could be used as a way of reducing $\mathrm{Na}^{+}$accumulation (and increasing $\mathrm{K}^{+}$) in rice and therefore growing rice in mildly saline environments. Furthermore, there was high genotypic contribution (27.5-41.7\%) for the observed variation for $\mathrm{Na}^{+}$and $\mathrm{K}^{+}$traits while there was a low treatment (water management) contribution (0.24-6.9\%). A small number of genotype by treatment interactions were found and some QTLs were detected in specific water treatments. These results indicate that the mechanism of both $\mathrm{Na}^{+}$and $\mathrm{K}^{+}$transport for plants under AWD and CF may be different but there are likely to be common mechanisms as well. The PC biplots (Fig. 2) showed that the $\mathrm{Na}^{+}$accumulation and $\mathrm{Na}^{+} / \mathrm{K}^{+}$ratio in shoots and grains were assigned together but were different with $\mathrm{K}^{+}$accumulation, and the $\mathrm{K}^{+}$ accumulation in shoots and grains were assigned into different directions. These results indicate that the $\mathrm{Na}^{+}$ accumulation and $\mathrm{Na}^{+} / \mathrm{K}^{+}$ratio are different to $\mathrm{K}^{+}$accumulation, and also that the $\mathrm{K}^{+}$accumulation in shoots and in grains are regulated differently. 
a

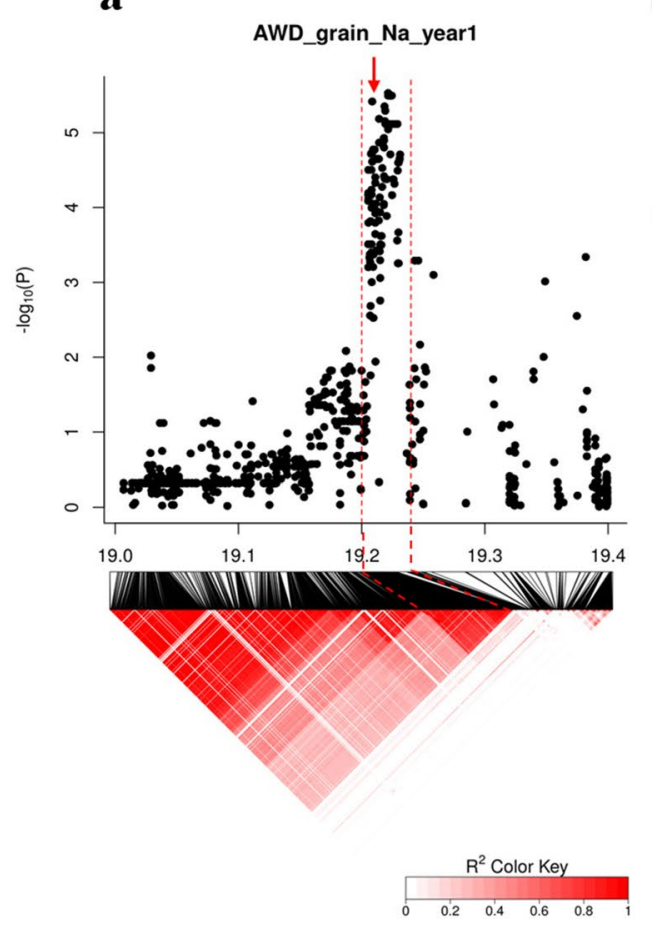

b

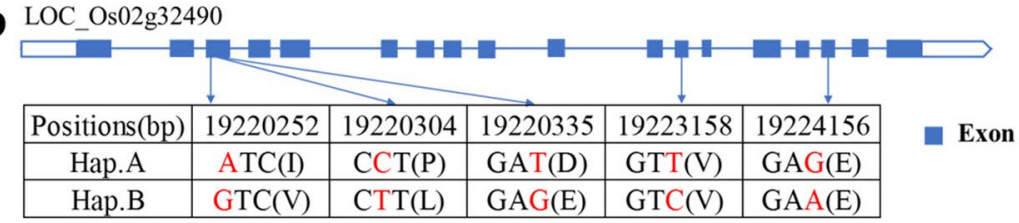

c
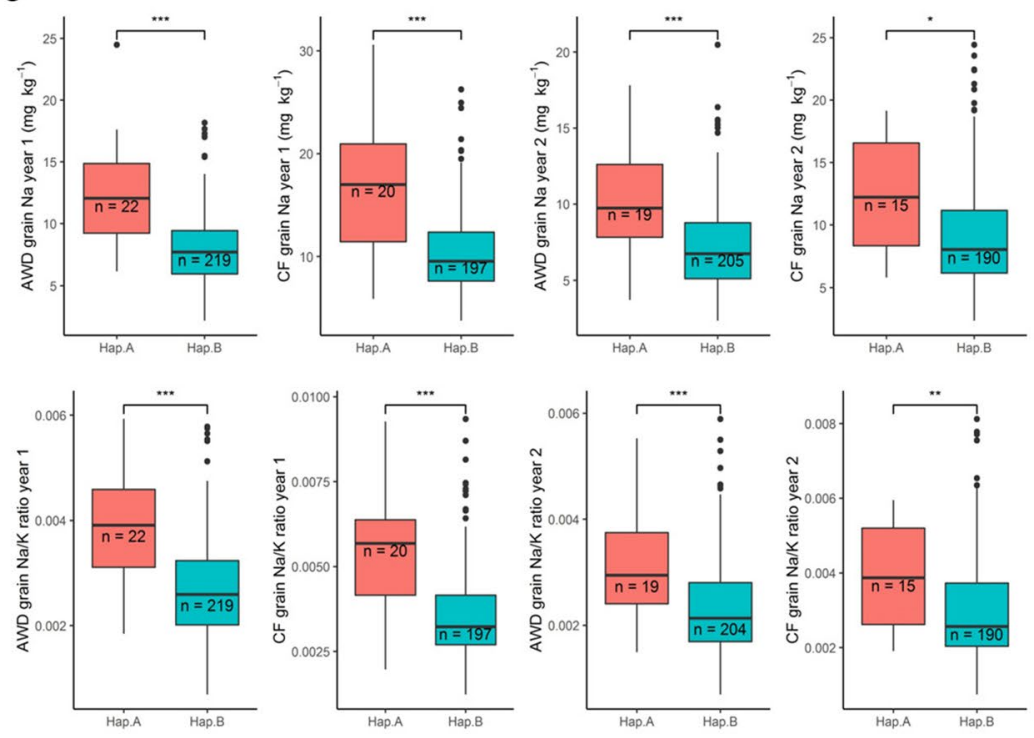

Fig. 7 Significant association for $\mathrm{Na}^{+}$concentration and $\mathrm{Na}^{+} / \mathrm{K}^{+}$ratio in the grains on chromosome $2-19.20 \mathrm{Mb}$. a Local Manhattan plot (top) and LD heat map (bottom) of QTL on Chromosome 2, dash line represents the candidate regions between 19.20 and $19.25 \mathrm{Mb}$, Arrow indicates the position of candidate gene LOC_OsO2g32490;

\section{Comparison of $\mathrm{Na}^{+}$concentration and $\mathrm{Na}^{+} / \mathrm{K}^{+}$ratio in different BAAP groups}

The BAAP population can be divided into five distinct groups based on population structure (Norton et al. 2018). There were differences in the accumulation of $\mathrm{Na}^{+}$and $\mathrm{K}^{+}$ for plants in these different groups (Fig. 3). Groups 1, 3 and 5 are predominantly from Bangladesh while groups 2 and 4 are predominantly from India (Norton et al. 2018). There were 28 cultivars in group 3 , of which 20 cultivars have the term "boro" in their names and are all from Bangladesh. The term "boro" refers to a growing season in Bangladesh and the Assam region during December-May, and also to the rice cultivars grown during this season, which are referred to as winter rice (GRiSP 2013; Khush 1997). Group 3 in this study showed high $\mathrm{Na}^{+}$concentration and $\mathrm{Na}^{+} / \mathrm{K}^{+}$ratio in grains and shoots but low $\mathrm{K}^{+}$ concentration in grains and shoots (Fig. 3). A total of 18 out of 29 cultivars in group 5 have the term "aus" in their names. "Aus" refers to a growing season in Bangladesh and Assam during April-August, and also to the cultivars grown in this season (GRiSP 2013; Travis et al. 2015). b the synonymous and nonsynonymous SNPs in the candidate gene LOC_OsO2g32490 significantly associated with the $\mathrm{Na}^{+}$, and amino acid variations; $\mathbf{c} \mathrm{Na}^{+}$concentration in grains for indicated haplotypes of LOC_OsO2g32490

These "aus" rice cultivars are broadcast, insensitive to photoperiod and are drought tolerant, and are referred to as summer rice (Khush 1997). Group 5 in this study showed low $\mathrm{Na}^{+}$concentration and $\mathrm{Na}^{+} / \mathrm{K}^{+}$ratio in grains and shoots while they were the highest in $\mathrm{K}^{+}$in shoots. These results indicate that the rice cultivars used to growing in the summer season have lower $\mathrm{Na}^{+}$accumulation and higher $\mathrm{K}^{+}$accumulation than the cultivars growing in the winter season.

The salt tolerance of these five groups in hydroponics and soil (under controlled environmental conditions) has previously been estimated (Chen et al. 2020). Group 3 cultivars, which have high shoot and grain $\mathrm{Na}^{+}$when grown in the field (Fig. 3), were previously identified as having high shoot $\mathrm{Na}^{+}$concentration and high salt sensitivity in both soil and hydroponic salt tolerance screens of seedlings. Similarly, cultivars in groups 1,4 and 5 , which have low $\mathrm{Na}^{+}$concentration and $\mathrm{Na}^{+} / \mathrm{K}^{+}$ratio in this study, had low shoot $\mathrm{Na}^{+}$ and were tolerant to $\mathrm{Na}^{+}$in the seedling screen (Chen et al. 2020). These results highlight the reliability of the tolerance tests and the value of measuring $\mathrm{Na}^{+}$concentration in field grown plants in the absence of salt stress. 


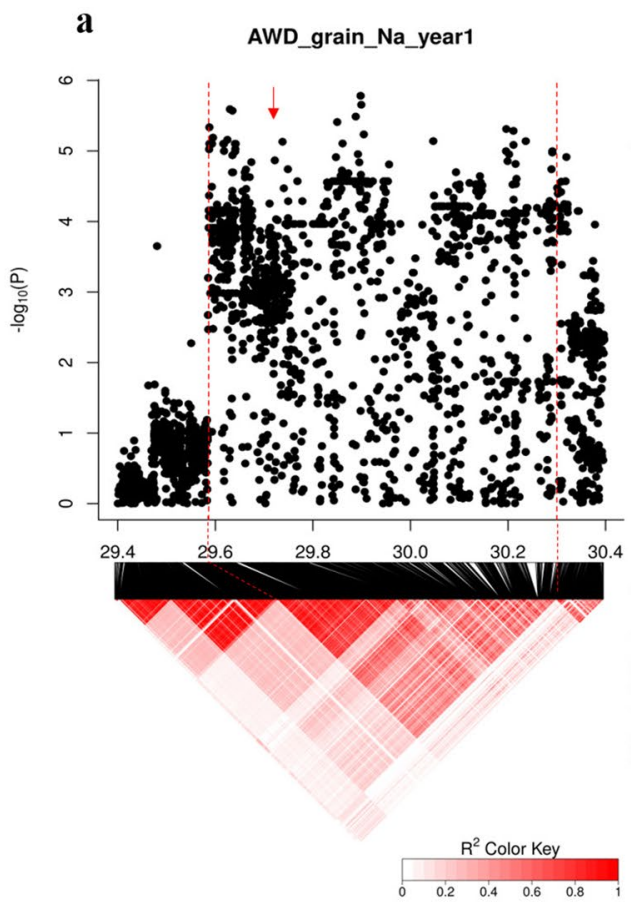

b
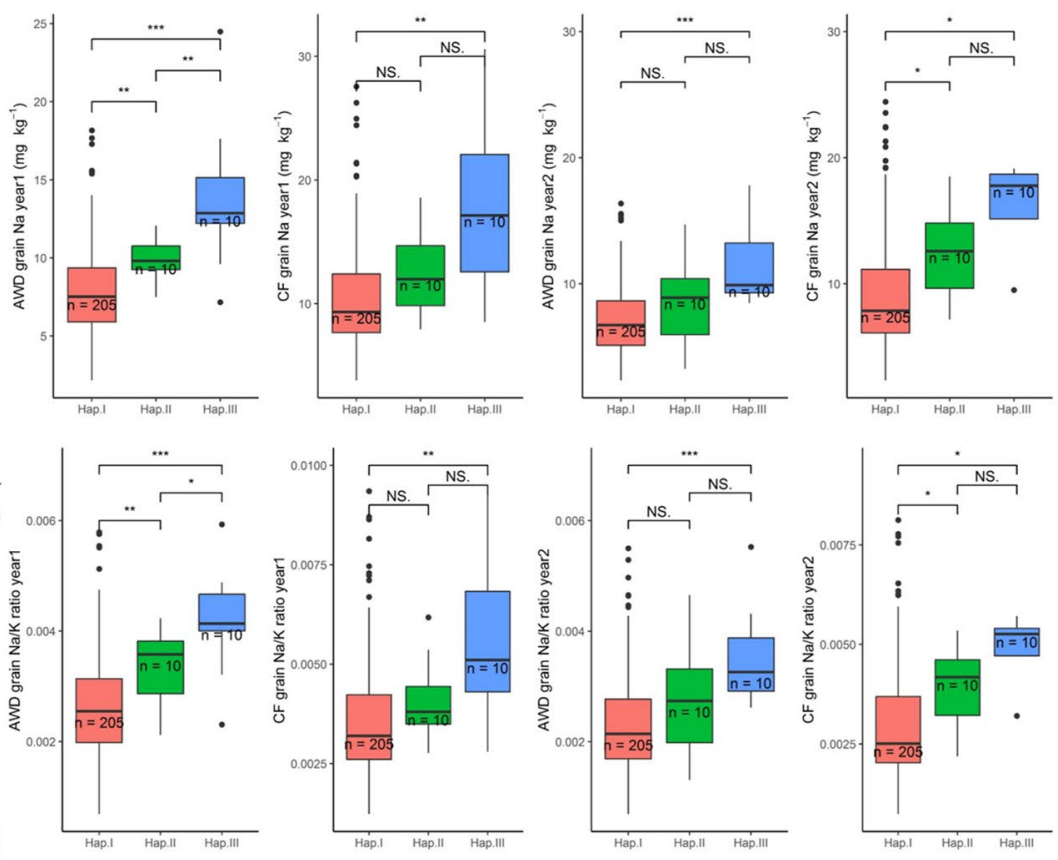

Fig. 8 Significant association for $\mathrm{Na}^{+}$concentration and $\mathrm{Na}^{+} / \mathrm{K}^{+}$ratio in the grains on chromosome $2-30.0 \mathrm{Mb}$. a Local Manhattan plot (top) and LD heat map (bottom) of QTL on Chromosome 2, dash line represents the candidate region between 29.59 and $30.30 \mathrm{Mb}$,

\section{QTLs}

A total of 106 QTLs were associated with the 12 traits in this study, and 48 of them were detected in multiple years and conditions. A comparison of QTLs detected in this study with the previously published QTLs for $\mathrm{Na}^{+}, \mathrm{K}^{+}$concentration and $\mathrm{Na}^{+} / \mathrm{K}^{+}$ratio showed that 32 QTLs were colocated (Fig. 9). For example, the QTL on chromosome 1 between 11.169 and $11.59 \mathrm{Mb}$, which was associated with 10 traits in this study, co-located with the Saltol, the major QTL ( 9.3-12.3 Mb) associated with $\mathrm{Na}^{+}$concentration and $\mathrm{Na}^{+} / \mathrm{K}^{+}$ratio (Koyama et al. 2001; Pandit et al. 2010; Islam et al. 2011; Kumar et al. 2015). This QTL has previously been identified as being associated with $\mathrm{Na}^{+}$accumulation under normal field conditions (Yang et al. 2018). The QTL on chromosome 1 between 27.08 and $27.32 \mathrm{Mb}$ was found to be associated with two traits here which were co-located with a previous QTL (Sabouri and Sabouri 2008; Hossain et al. 2015). The QTL on chromosome 11 between 17.61 and $17.85 \mathrm{Mb}$, which was associated with three traits in this study was co-located with a QTL in a previous GWA study for $\mathrm{Na}^{+} / \mathrm{K}^{+}$ratio (Batayeva et al. 2018). These results suggest the QTLs identified in this study are real and stable. There are still a number of notable QTLs identified in this study which have not been reported previously and were
Arrow indicates the position of candidate gene $L O C \_O s 02 g 48560$ (OsFAD2_1) (Positioned at $29.73 \mathrm{Mb}$ ); $\mathbf{b ~ N a}{ }^{+}$concentration and $\mathrm{Na}^{+} /$ $\mathrm{K}^{+}$ratio in grains for indicated haplotypes of $L O C \_O s 02 g 48560$

identified as being associated with multiple traits/conditions. For instance, the QTL on chromosome $2-19.2 \mathrm{Mb}$ was associated with four traits, the QTL on chromosome 2-29.9 Mb was associated with two traits and the QTL on chromosome 7-12.78 Mb was associated with four traits. As these QTLs were detected in multiple traits it suggests they are stable, and as they have not been previously detected it could suggest that they are specific for aus rice cultivars.

Some of the QTLs detected here appear to be tissue specific but some are not. There were several QTLs for $\mathrm{Na}^{+}$ concentration detected in both grains and shoots, while some QTLs were only detected in either grains or shoots (Table 2). The QTL on chromosome 1 between 11.24 and $11.59 \mathrm{Mb}$, the QTL on chromosome 4-27.36 Mb and QTL on chromosome 11 between 25.63 and $26.06 \mathrm{Mb}$ were detected in both shoot $\mathrm{Na}^{+}$and grain $\mathrm{Na}^{+}$. In contrast, the $\mathrm{Na}^{+}$QTLs on chromosome 1 between 0.86 and $1.06 \mathrm{Mb}$, on chromosome $2-19.20 \mathrm{Mb}$ and on chromosome $2-29.80 \mathrm{Mb}$ were detected only in grains, and the $\mathrm{Na}^{+}$QTLs on chromosome 1-13.17 Mb and on chromosome 4-28.2 Mb were only detected in shoots (Table 2).

A comparison of the106 QTLs detected here in field conditions with the QTLs for salt tolerance identified under salt stress in hydroponic and soil systems in the same BAAP population (Chen et al. 2020) showed 16 and 13 of the QTLs 
Fig. 9 Locations of the QTLs for $\mathrm{Na}^{+}, \mathrm{K}^{+}$concentration and $\mathrm{Na}^{+} / \mathrm{K}^{+}$ratio detected in this study and in previously studies. Candidate genes identified in this study were indicated by horizontal lines

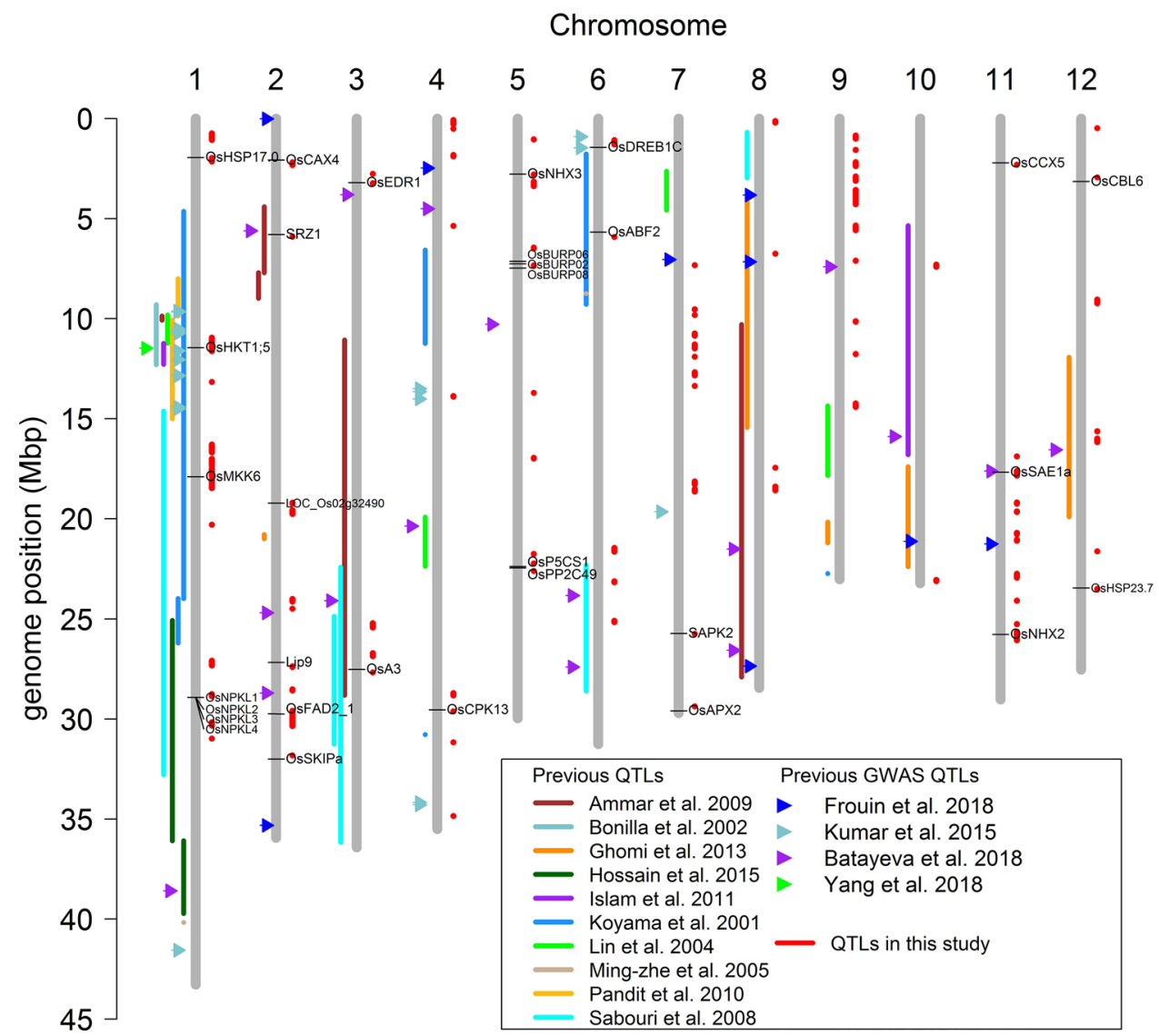

were co-located with the QTLs for salt tolerance detected in the hydroponic and soil system, respectively (Table S6). Four of these QTLs were found in all three experiments. The first is the QTL on chromosome 1 between 16.29 and 16.69 $\mathrm{Mb}$ which was detected to be associated with shoot $\mathrm{Na}^{+}$concentration and $\mathrm{Na}^{+} / \mathrm{K}^{+}$ratio in field conditions, with relative root length (root length in salinity stress versus root length in control conditions) in the hydroponic environment and with shoot $\mathrm{Na}^{+}$concentration in the soil environment. The second QTL was on chromosome 4-29.61 Mb and was found to be associated with shoot $\mathrm{Na}^{+} / \mathrm{K}^{+}$ratio in field conditions, with salt injury score in the hydroponic environment, and with relative shoot length in the soil environment. The third QTL was on chromosome 7-9.54 Mb and was found to be associated with grain $\mathrm{Na}^{+}$concentration in field conditions, with shoot $\mathrm{Na}^{+}$concentration in the hydroponic environment and with shoot $\mathrm{Na}^{+} / \mathrm{K}^{+}$ratio in the soil environment. The fourth QTL was on chromosome 12 between 15.99 and $16.17 \mathrm{Mb}$ and was identified as being associated with grain $\mathrm{Na}^{+}$concentration in the field, with salt injury score in the hydroponic environment and with relative tiller number (tiller number in salinity stress versus tiller number in control condition) in the soil environment. The traits measured in the field were under normal conditions without salt stress imposed while the traits in hydroponic and soil system were in moderate salt stress conditions. The QTLs which were detected in salt stress and non-salt stress conditions may indicate that these QTLs regulate the $\mathrm{Na}^{+}, \mathrm{K}^{+}$ accumulation and not just expressed in salt stress.

\section{Candidate genes}

A total of 31 candidate genes which have been previously reported to be involved in salt stress and/or sodium accumulation were found to be within $\pm 243 \mathrm{~Kb}$ of the peak SNP (the global LD decay of the BAAP population (Norton et al. 2018)) (Fig. 9 and Table S11). Several candidate genes are ion transporters. The most notable one, gene OsHKT1;5, a $\mathrm{Na}^{+}$transporter, was found under the QTL on chromosome 1 between 11.24 and $11.59 \mathrm{Mb}$. OsHKT1;5 is a $\mathrm{Na}^{+}$ selective transporter involved in $\mathrm{Na}^{+}$and $\mathrm{K}^{+}$homeostasis (Ren et al. 2005), and is also reported to be involved in $\mathrm{Na}^{+}$ accumulation in normal field condition (Yang et al. 2018). Here, three haplotypes were found in aus cultivars based on five SNPs in the exon significantly associated with $\mathrm{Na}^{+}$ concentration. The cultivars carrying A and B haplotypes had lower $\mathrm{Na}^{+}$concentration in grains and shoots than the cultivars carrying the $\mathrm{C}$ haplotype. The haplotype $\mathrm{A}$ is the rarest haplotype in the BAAP and is only present in 10 of the cultivars. Four non-synonymous SNPs with the amino acid 
substitutions (S2N, P140A, H184R, Q429K) were presented. These four amino acid substitutions were reported in the study of Yang et al. (2018) from 529 rice cultivars, and they indicated the H184R is likely the key substitution that causes functional variation in $O s H K T 1 ; 5$ (Yang et al. 2018). The P140A alteration was reported to increase the probability of OsHKT1;5 phosphorylation (Negrão et al. 2013). It was reported that the haplotypes of OsHKT1;5 in Goria (which was identified as a salt tolerant cultivar under salt stress in hydroponic and soil experiments) in the BAAP were identical to one accession called Nona Bokra (IRS_313-7736) (salt tolerance check), while different to Pokkali (IRIS_3138244) (salt tolerance check) and another accession called Nona Bora (CX273) based on 92 SNPs (Chen et al. 2020).

OsNHX3 and $O s N H X 2$, the monovalent cation: proton antiporters, having a role of compartmentation of $\mathrm{Na}^{+}$and $\mathrm{K}^{+}$accumulated in the cytoplasm into vacuoles, were found in the QTL region located on chromosome $5-2.80 \mathrm{Mb}$, and in the QTL on chromosome 11-25.80 Mb, respectively. Expression analysis of the $O S N H X 3$ gene in rice indicates that it is highly expressed in the flag leaf and blades (Fukuda et al. 2011). Sodium chloride stress resulted in an increase in transcript abundance in the roots and shoots of $O s N H X 3$ (Fukuda et al. 2011). Expression analysis of $O s N H X 2$ in rice indicates that it is highly expressed in the flag leaf, sheaths, culms and panicles (Fukuda et al. 2011). Sodium chloride stress resulted in an increase in transcript abundance in the roots and shoots (Fukuda et al. 2011). OsNHX2 can enhance salt tolerance in rice through more effective accumulation of toxic $\mathrm{Na}^{+}$in leaf mesophyll and bundle sheath cells (Teng et al. 2017). In this study, seven SNPs in the exons of OsNHX2 were found to be significantly associated with $\mathrm{Na}^{+}$ concentration, in which two were non-synonymous SNPs. Two haplotypes of these seven polymorphisms were found in the BAAP; the B haplotype significantly decreased the $\mathrm{Na}^{+}$concentration in grains but studies of allelic variation on this gene have not been conducted.

For the QTL on chromosome 2-19.2 Mb, five genes were found in the QTL local LD region (19.20-19.24 Mb). To identify which of these genes are potential candidate genes, the expression profiles of these genes were explored. Previously it has been demonstrated that the RNA expression levels of LOC_Os02g32490 (ACS1) were significantly upregulated under salt and osmotic stress (Buti et al. 2019). The RNA expression between salt tolerance and salt sensitive cultivars were also significant under control conditions (Walia et al. 2007). Additionally, there was a significant difference in RNA expression for this gene between rice cultivars from the indica and japonica subpopulations (Campbell et al. 2020). LOC_OsO2g32490 is annotated as an AMP-binding enzyme from the RGAP and was reported as encoding acetyl-CoA synthetase1 (Kaya et al. 2017). Two haplotypes were found in five SNPs in the exon of this gene in the BAAP, and the $\mathrm{B}$ haplotype had low grain $\mathrm{Na}^{+}$and $\mathrm{Na}^{+} / \mathrm{K}^{+}$ratio (Fig. 7). The function between this gene and $\mathrm{Na}^{+}$accumulation needs to be explored.

The QTL on chromosome 2-29.9 Mb detected in this study was also found to be associated with $\mathrm{Na}^{+}$concentration and $\mathrm{Na}^{+} / \mathrm{K}^{+}$ratio under salt stress in hydroponic experiments (Chen et al. 2020). LOC_OsO2g48560 (OsFAD2_1), a fatty acid desaturase was proposed as the potential candidate gene for this QTL. Excess salt causes ion toxicity inside the cell and creates hyperosmotic stress in plants, thereby causing secondary stresses, such as oxidative stress resulting from the accumulation of reactive oxygen species (ROS) (Zhu 2001). Stress acclimating plants respond to abiotic and biotic stress by remodeling membrane fluidity and by releasing $\alpha$-linolenic acid from membrane lipids. The modification of membrane fluidity is mediated by changes in unsaturated fatty acid levels, a function provided in part by the regulated activity of fatty acid desaturases (Zhu 2001, Zhiguo et al. 2019). Fatty acid desaturases play an important role in fatty acid metabolism and maintenance of the biological function of membranes in plant cells (Singh et al. 2002; Kaya et al. 2017; Sui et al. 2017). It has been suggested that omega-3 fatty acid desaturase overexpression can enhance the tolerance of early seedlings to salinity stress in tomato plants, by maintaining the integrity of the membrane system (Wang et al. 2014). Sui et al. (2018) reported salt stress markedly changed the activity of a fatty acid desaturase and fatty acid composition in peanut plants. RNA expression of LOC_OsO2g48560 (OsFAD2_1) under salt and osmotic stress was significantly downregulated (Buti et al. 2019). These results indicate that fatty acid desaturase may also play an important role in rice in response to stress, but it must be noted that no nonsynonymous SNPs within this gene were detected in the BAAP.

\section{Combined low Na haplotypes}

It is interesting to note that for all the QTLs discussed in all cases, the most common haplotypes are for low $\mathrm{Na}^{+}$concentration. To identify if any accessions have multiple low haplotypes, the haplotype variations of four candidate genes in four notable QTLs were analyzed. Among 266 aus rice accessions in the BAAP, 130 of them carry low $\mathrm{Na}^{+}$haplotypes across all four QTLs. The cultivars BOWALIA 2, T 65, T 1, and AUS 125, which were reported to be more salt tolerant than the check genotype (Pokkali) under salt stress in hydroponic and soil experiments (Chen et al. 2020) were all carrying the low $\mathrm{Na}^{+}$haplotypes (Table S1). The results show that most of the accessions in the BAAP already have low $\mathrm{Na}^{+}$haplotypes for breeding and these accessions can be used for confirming the presence of low $\mathrm{Na}^{+}$rice breeding materials, and can also be used for breeding lower $\mathrm{Na}^{+}$ accumulation in rice. 
To determine if these common alleles of the four candidate genes in the aus rice are also common in the indica and japonica rice, the haplotypes analysis tool RiveVarMap (Zhao et al. 2015) which included the cultivars from the Rice Diversity Panel were employed (Table S12). The common alleles of OsHKT1;5 (Hap. B) and OsFAD2_l (Hap. I) in the aus rice are the rare alleles in both indica and japonica rice. The common allele of $O s N H X 2$ (Hap. A) in the aus rice is the common allele in the indica and japonica rice. The common allele (Hap. B) of LOC_OsO2g32490 in the aus rice is the common allele of japonica rice while it is the rare allele of indica rice.

\section{$\mathrm{Na}^{+}$concentration under salt stress and non-salt stress}

The $\mathrm{Na}^{+}$concentration of the BAAP was previously evaluated under salt stress in hydroponic and soil-based environments (Chen et al. 2020). In this study, the $\mathrm{Na}^{+}$concentration of the BAAP was measured in a non-salt stress field environment. There were significant correlations of $\mathrm{Na}^{+}$ concentration under salt stress and non-salt stress conditions (Table S5). The salt tolerant cultivars (BOWALIA 2, T 65, $\mathrm{T} 1$ and AUS 125), identified under salt stress in hydroponic and soil experiments (Chen et al. 2020), were carrying the low $\mathrm{Na}^{+}$haplotypes reported in the current study. Additionally, several QTLs for $\mathrm{Na}^{+}$concentration identified in non-salt stress conditions were co-located with the QTLs identified in salt stress conditions. For instance, the notable QTL on chromosome 1-11.45 Mb (same chromosome position as the well know QTL Saltol) which was found to be associated with $\mathrm{Na}^{+}$concentration in this study (non-salt stress in field) was also identified as being associated with $\mathrm{Na}^{+}$in the hydroponic experiment (salt stress) (Table S6). This QTL was also associated with $\mathrm{Na}^{+}$accumulation in 529 rice cultivars in field experiments without salt stress imposed (Yang et al. 2018). The gene OsHKTI;5, regulating $\mathrm{K}^{+} / \mathrm{Na}^{+}$homeostasis under salt stress (Ren et al. 2005), was also detected for $\mathrm{Na}^{+}$accumulation in non-salt stress (Yang et al. 2018). These results indicate that the mechanisms and genes regulating $\mathrm{Na}^{+}$concentration in the absence of salt stress are relevant for salt tolerance.

\section{Conclusion}

In this study, we evaluated the $\mathrm{Na},{ }^{+} \mathrm{K}^{+}$concentration and $\mathrm{Na}^{+} / \mathrm{K}^{+}$ratio in grains and shoots of the BAAP population with 300 cultivars under the AWD and $\mathrm{CF}$ water treatments over 2 years. The $\mathrm{Na}^{+}$concentration and $\mathrm{Na}^{+} / \mathrm{K}^{+}$ratio of plants grown under AWD conditions were significantly lower than plants grown under $\mathrm{CF}$, while $\mathrm{K}^{+}$concentration in plants grown under AWD were significantly higher than that in $\mathrm{CF}$ (except for the grain $\mathrm{K}^{+}$in year 2). The $\mathrm{Na}^{+}$concentration in shoots and grains in the field were positively significantly correlated with $\mathrm{Na}^{+}$concentration in shoots under salt stress in both hydroponics and in soil experiments. A GWA study was conducted for these 18 traits and a total of 106 QTLs were identified, with 48 of them being found to be associated with multiple traits. The haplotypes analysis of four candidate genes in four notable QTLs was investigated. The low $\mathrm{Na}^{+}$accumulation cultivars and QTLs for $\mathrm{Na}^{+}$identified in this study could provide some useful information for future studies on breeding of low $\mathrm{Na}^{+}$accumulation rice.

Supplementary Information The online version contains supplementary material available at https://doi.org/10.1007/s00122-021-03828-9.

Acknowledgements We acknowledge Dr. Wenchuang for his support in providing help during the analysis of the data.

Authors' contribution statement $\mathrm{AP}$ and GN designed the experiment. $\mathrm{MH}$ and MI conducted the field experiments, AT developed the GWAS pipeline, CC, AP and GN performed data analysis and wrote the first draft of the manuscript. All authors read and approved the manuscript.

Funding The production of the BAAP was conducted under BBSRC funded project BB/J003336/1, with minor development under BB/ N013492/1. The first author gratefully acknowledges financial support from China Scholarship Council.

Data availability The phenotype data used for the genome-wide association mapping is available in supplementary Table 1. The SNP dataset is available as a project called "BAAP" in the SNP-Seek database and on the Harvard DataVerse as a dataset called "Genome Wide Association mapping of grain and straw biomass traits in the rice Bengal and Assam Aus Panel (BAAP).”

\section{Declarations}

Conflict of interest The authors declare that they do not have any conflict of interest.

Open Access This article is licensed under a Creative Commons Attribution 4.0 International License, which permits use, sharing, adaptation, distribution and reproduction in any medium or format, as long as you give appropriate credit to the original author(s) and the source, provide a link to the Creative Commons licence, and indicate if changes were made. The images or other third party material in this article are included in the article's Creative Commons licence, unless indicated otherwise in a credit line to the material. If material is not included in the article's Creative Commons licence and your intended use is not permitted by statutory regulation or exceeds the permitted use, you will need to obtain permission directly from the copyright holder. To view a copy of this licence, visit http://creativecommons.org/licenses/by/4.0/.

\section{References}

Ali S, Gautam RK, Mahajan R et al (2013) Stress indices and selectable traits in SALTOL QTL introgressed rice genotypes for 
reproductive stage tolerance to sodicity and salinity stresses. Field Crop Res 154:65-73. https://doi.org/10.1016/j.fcr.2013.06.011

Allen SE, Grimshaw HM, Parkinson JA, Quarmby C (1974) Chemical analysis of ecological materials. Blackwell Scientific Publications

Ammar MHM, Pandit A, Singh RK et al (2009) Mapping of QTLs controlling $\mathrm{Na}^{+}, \mathrm{K}^{+}$and $\mathrm{Cl}^{-}$Ion concentrations in salt tolerant Indica rice variety CSR27. J Plant Biochem Biotechnol 18:139-150. https://doi.org/10.1007/bf03263312

An H, Liu K, Wang B et al (2020) Genome-wide association study identifies QTLs conferring salt tolerance in rice. Plant Breed 139:73-82. https://doi.org/10.1111/pbr.12750

Batayeva D, Labaco B, Ye C et al (2018) Genome-wide association study of seedling stage salinity tolerance in temperate japonica rice germplasm. BMC Genet 19:1-11. https://doi.org/10.1186/ s12863-017-0590-7

Belder P, Bouman BAM, Cabangon R et al (2004) Effect of watersaving irrigation on rice yield and water use in typical lowland conditions in Asia. Agric Water Manag 65:193-210. https://doi. org/10.1016/j.agwat.2003.09.002

Benjamini Y, Hochberg Y (1995) Controlling the false discovery rate: a practical and powerful approach to multiple testing. J R Stat Soc Ser B 57:289-300

Bonilla P, Dvorak J, Mackill D et al (2002) RFLP and SSLP mapping of salinity tolerance genes in chromosome 1 of rice (Oryza sativa L.) using recombinant inbred lines. Philipp Agric Sci 65:68-76

Bouman B (2009) How much water does rice need. Rice Today (International Rice Res Institute) 8:44

Bouman BAM, Tuong TP (2001) Field water management to save water and increase its productivity in irrigated lowland rice. Agric Water Manag 49:11-30. https://doi.org/10.1016/S0378-3774(00) 00128-1

Buti M, Baldoni E, Formentin E et al (2019) A meta-analysis of comparative transcriptomic data reveals a set of key genes involved in the tolerance to abiotic stresses in rice. Int J Mol Sci 20:1-30. https://doi.org/10.3390/ijms20225662

Campbell MT, Campbell MT, Du Q et al (2020) Characterization of the transcriptional divergence between the subspecies of cultivated rice (Oryza sativa). BMC Genomics 21:1-16. https://doi.org/10. 1186/s12864-020-06786-6

Carrijo DR, Lundy ME, Linquist BA (2017) Rice yields and water use under alternate wetting and drying irrigation: a meta-analysis. Field Crop Res 203:173-180. https://doi.org/10.1016/j.fcr.2016. 12.002

Chen C, Norton GJ, Price AH (2020) Genome-Wide association mapping for salt tolerance of rice seedlings grown in hydroponic and soil systems using the Bengal and Assam aus panel. Front Plant Sci 11:1-18. https://doi.org/10.3389/fpls.2020.576479

Chou ML, Jean JS, Sun GX et al (2016) Irrigation practices on rice crop production in arsenic-rich paddy soil. Crop Sci 56:422-431. https://doi.org/10.2135/cropsci2015.04.0233

Frouin J, Languillaume A, Mas J et al (2018) Tolerance to mild salinity stress in japonica rice: a genome-wide association mapping study highlights calcium signaling and metabolism genes. PLoS ONE. https://doi.org/10.1371/journal.pone.0190964

Fukuda A, Nakamura A, Hara N et al (2011) Molecular and functional analyses of rice NHX-type $\mathrm{Na}^{+} / \mathrm{H}^{+}$antiporter genes. Planta 233:175-188. https://doi.org/10.1007/s00425-010-1289-4

Garris AJ, Tai TH, Coburn J et al (2005) Genetic structure and diversity in Oryza sativa L. Genetics 169:1631-1638. https://doi.org/10. 1534/genetics.104.035642

Ghomi K, Rabiei B, Sabouri H, Sabouri A (2013) Mapping QTLs for traits related to salinity tolerance at seedling stage of rice (Oryza sativa L.): an agrigenomics study of an Iranian rice population. OMICS 17:242-251. https://doi.org/10.1089/omi.2012.0097
Glaszmann JC (1987) Isozymes and classification of Asian rice varieties. Theor Appl Genet 74:21-30. https://doi.org/10.1007/BF002 90078

GRiSP (Global Rice Science Partnership). (2013) Rice almanac, 4th edn. International Rice Research Institute, Los Baños (Philippines), p 283

Hossain H, Rahman MA, Alam MS, Singh RK (2015) Mapping of quantitative trait loci associated with reproductive-stage salt tolerance in rice. J Agron Crop Sci 201:17-31. https://doi.org/10. $1111 /$ jac. 12086

Hu S, Tao H, Qian Q, Guo L (2012) Genetics and molecular breeding for salt-tolerance in rice. Rice Genom Genet 3:39-49. https://doi. org/10.5376/rgg.2012.03.0007

Islam M, Rahman M, Mian M, Ali M (2016) Effect of fertilizer management on npks leaching loss from sandy loam soil under alternate wetting and drying condition. Bangladesh Rice J 20:59-64. https://doi.org/10.3329/brj.v20i1.30630

Islam MR, Salam MA, Hassan L et al (2011) QTL mapping for salinity tolerance at seedling stage in rice. Emirates J Food Agric 23:137-146. https://doi.org/10.9755/ejfa.v23i2.6348

Kaya H, Numa H, Nishizawa-Yokoi A et al (2017) DNA methylation affects the efficiency of transcription activator-like effector nucleases-mediated genome editing in rice. Front Plant Sci 8:1-4. https://doi.org/10.3389/fpls.2017.00302

Khush GS (1997) Origin, dispersal, cultivation and variation of rice. Plant Mol Biol 35:25-34. https://doi.org/10.1007/ 978-94-011-5794-0_3

Kim HJ, Jung J, Singh N et al (2016) Population Dynamics among six major groups of the Oryza rufipogon Species complex, wild relative of cultivated Asian rice. Rice. https://doi.org/10.1186/ s12284-016-0119-0

Koyama ML, Levesley A, Koebner RMD et al (2001) Quantitative trait loci for component physiological traits determining salt tolerance in rice. Plant Physiol 125:406-422. https://doi.org/ 10.1104/pp.125.1.406

Kumar V, Singh A, Mithra SVA et al (2015) Genome-wide association mapping of salinity tolerance in rice (Oryza sativa). DNA Res 22:133-145. https://doi.org/10.1093/dnares/dsu046

Lampayan RM, Rejesus RM, Singleton GR, Bouman BAM (2015) Adoption and economics of alternate wetting and drying water management for irrigated lowland rice. Field Crop Res 170:95108. https://doi.org/10.1016/j.fcr.2014.10.013

Lin HX, Zhu MZ, Yano M et al (2004) QTLs for $\mathrm{Na}^{+}$and $\mathrm{K}^{+}$ uptake of the shoots and roots controlling rice salt tolerance. Theor Appl Genet 108:253-260. https://doi.org/10.1007/ s00122-003-1421-y

Linquist BA, Anders MM, Adviento-Borbe MAA et al (2015) Reducing greenhouse gas emissions, water use, and grain arsenic levels in rice systems. Glob Chang Biol 21:407-417. https://doi.org/10. $1111 / \mathrm{gcb} .12701$

McCouch SR, Wright MH, Tung C-W et al (2016) Open access resources for genome-wide association mapping in rice. Nat Commun 7:1-14

Ming-Zhe Y, Jian-Fei W, Hong-You C et al (2005) Inheritance and QTL mapping of salt tolerance in rice. Rice Sci 12:25-32

Negrão S, Cecília Almadanim M, Pires IS et al (2013) New allelic variants found in key rice salt-tolerance genes: an association study. Plant Biotechnol J 11:87-100. https://doi.org/10.1111/pbi.12010

Negrão S, Courtois B, Ahmadi N et al (2011) Recent updates on salinity stress in rice: from physiological to molecular responses. CRC Crit Rev Plant Sci 30:329-377. https://doi.org/10.1080/07352689. 2011.587725

Norton GJ, Duan GL, Lei M et al (2012) Identification of quantitative trait loci for rice grain element composition on an arsenic impacted soil: influence of flowering time on genetic loci. Ann 
Appl Biol 161:46-56. https://doi.org/10.1111/j.1744-7348.2012. 00549.x

Norton GJ, Shafaei M, Travis AJ et al (2017a) Impact of alternate wetting and drying on rice physiology, grain production, and grain quality. F Crop Res 205:1-13. https://doi.org/10.1016/j.fcr.2017. 01.016

Norton GJ, Travis AJ, Danku JMC et al (2017b) Biomass and elemental concentrations of 22 rice cultivars grown under alternate wetting and drying conditions at three field sites in Bangladesh. Food Energy Secur 6:98-112. https://doi.org/10.1002/fes3.110

Norton GJ, Travis AJ, Douglas A et al (2018) Genome wide association mapping of grain and straw biomass traits in the rice bengal and assam aus panel (BAAP) grown under alternate wetting and drying and permanently flooded irrigation. Front Plant Sci 9:1-18. https://doi.org/10.3389/fpls.2018.01223

Norton GJ, Travis AJ, Talukdar P et al (2019) Genetic loci regulating arsenic content in rice grains when grown flooded or under alternative wetting and drying irrigation. Rice 12:54

Pandit A, Rai V, Bal S et al (2010) Combining QTL mapping and transcriptome profiling of bulked RILs for identification of functional polymorphism for salt tolerance genes in rice (Oryza sativa L.). Mol Genet Genomics 284:121-136. https://doi.org/10.1007/ s00438-010-0551-6

Patishtan J, Hartley TN, Fonseca de Carvalho R, Maathuis FJM (2018) Genome-wide association studies to identify rice salt-tolerance markers. Plant Cell Environ 41:970-982

Purcell S, Neale B, Todd-Brown K et al (2007) PLINK: a tool set for whole-genome association and population-based linkage analyses. Am J Hum Genet 81:559-575. https://doi.org/10.1086/519795

Ren ZH, Gao JP, Li LG et al (2005) A rice quantitative trait locus for salt tolerance encodes a sodium transporter. Nat Genet 37:11411146. https://doi.org/10.1038/ng1643

Rohila JS, Edwards JD, McClung AM et al (2019) Identification of superior alleles for seedling stage salt tolerance in the USDA rice minicore collection. Plants 8:1-23. https://doi.org/10.3390/plants8110472

Sabouri H, Sabouri A (2008) New evidence of QTLs attributed to salinity tolerance in rice. African J Biotechnol 7:4376-4383

Shankar R, Bhattacharjee A, Jain M (2016) Transcriptome analysis in different rice cultivars provides novel insights into desiccation and salinity stress responses. Sci Rep 6:1-15. https://doi.org/10. 1038/srep23719

Singh SC, Sinha RP, Häder DP (2002) Role of lipids and fatty acids in stress tolerance in cyanobacteria. Acta Protozool 41:297-308

Solis CA, Yong MT, Vinarao R et al (2020) Back to the wild: on a quest for donors toward salinity tolerant rice. Front Plant Sci 11:323. https://doi.org/10.3389/fpls.2020.00323

Sui N, Tian S, Wang W et al (2017) Overexpression of glycerol-3-phosphate acyltransferase from suaeda salsa improves salt tolerance in arabidopsis. Front Plant Sci 8:1-14. https://doi.org/10.3389/ fpls.2017.01337

Sui N, Wang Y, Liu S et al (2018) Transcriptomic and physiological evidence for the relationship between unsaturated fatty acid and salt stress in peanut. Front Plant Sci 9:1-12. https://doi.org/10. 3389/fpls.2018.00007
Teng XX, Cao WL, Lan HX et al (2017) OsNHX2, an $\mathrm{Na}^{+} / \mathrm{H}^{+}$antiporter gene, can enhance salt tolerance in rice plants through more effective accumulation of toxic $\mathrm{Na}^{+}$in leaf mesophyll and bundle sheath cells. Acta Physiol Plant. https://doi.org/10.1007/ s11738-017-2411-z

Travis AJ, Norton GJ, Datta S et al (2015) Assessing the genetic diversity of rice originating from Bangladesh, Assam and West Bengal. Rice 8:1-9. https://doi.org/10.1186/s12284-015-0068-z

Visconti F, de Paz JM, Rubio JL (2010) What information does the electrical conductivity of soil water extracts of 1 to 5 ratio $(\mathrm{w} / \mathrm{v})$ provide for soil salinity assessment of agricultural irrigated lands? Geoderma 154:387-397. https://doi.org/10.1016/j.geoderma. 2009.11.012

Walia H, Wilson C, Zeng L et al (2007) Genome-wide transcriptional analysis of salinity stressed japonica and indica rice genotypes during panicle initiation stage. Plant Mol Biol 63:609-623. https://doi.org/10.1007/s11103-006-9112-0

Wang K, Li M, Hakonarson H (2010) ANNOVAR: functional annotation of genetic variants from high-throughput sequencing data. Nucleic Acids Res 38:1-7. https://doi.org/10.1093/nar/gkq603

Wang HS, Yu C, Tang XF, et al (2014) A tomato endoplasmic reticulum (ER)-type omega-3 fatty acid desaturase (LeFAD3) functions in early seedling tolerance to salinity stress. Plant Cell Rep 33:131-142. https://doi.org/10.1007/s00299-013-1517-z

Yang J, Liu K, Wang Z et al (2007) Water-saving and high-yielding irrigation for lowland rice by controlling limiting values of soil water potential. J Integr Plant Biol 49:1445-1454. https://doi.org/ 10.1111/j.1672-9072.2007.00555.x

Yang M, Lu K, Zhao FJ et al (2018) Genome-wide association studies reveal the genetic basis of ionomic variation in rice. Plant Cell 30:2720-2740. https://doi.org/10.1105/tpc.18.00375

Zhang H, Xue Y, Wang Z et al (2009) An alternate wetting and moderate soil drying regime improves root and shoot growth in rice. Crop Sci 49:2246-2260. https://doi.org/10.2135/cropsci2009.02.0099

Zhao H, Yao W, Ouyang Y et al (2015) RiceVarMap: a comprehensive database of rice genomic variations. Nucleic Acids Res 43:D1018-D1022. https://doi.org/10.1093/nar/gku894

Zhao K, Wright M, Kimball J et al (2010) Genomic diversity and introgression in $O$. sativa reveal the impact of domestication and breeding on the rice genome. PLoS ONE. https://doi.org/10.1371/ journal.pone.0010780

Zhiguo E, Chen C, Yang J et al (2019) Genome-wide analysis of fatty acid desaturase genes in rice (Oryza sativa L.). Sci Rep 9:1-11. https://doi.org/10.1038/s41598-019-55648-z

Zhu JK (2001) Plant salt tolerance. Trends Plant Sci. https://doi.org/ 10.1016/S1360-1385(00)01838-0

Publisher's Note Springer Nature remains neutral with regard to jurisdictional claims in published maps and institutional affiliations. 